\title{
Mental health interventions and priorities for research for adult survivors of torture and systematic violence: a review of the literature
}

\author{
William M. Weiss, Dr.PH*, Ana M. Ugueto, PhD**, Zayan Mahmooth*, MSPH, Laura \\ K. Murray, PhD**, Brian J. Hall, PhD****, Maya Nadison, PhD**, Andrew Rasmussen, \\ PhD***, Jennifer S. Lee, MSPH*, Andrea Vazzano, MPH**, Judy Bass, PhD**, Paul \\ Bolton, MBBS*,**
}

\begin{abstract}
This research describes the development and findings of a literature review and analysis meant to inform the international torture and trauma treatment community. The review focuses on interventions that have been used among populations affected by torture, based on a review of journals indexed in commonly used search engines. Work on the review began in September 2008 and continued to be updated until March 2014. In total, 88 studies of interventions for torture victims were identified. Studies ranged from randomized controlled trials utilizing evidence-based treatments to case studies employing non-structured, supportive therapies. Based on the results of the analysis, we have included recommenda-
\end{abstract}

\footnotetext{
^) Johns Hopkins Bloomberg School of Public Health, Department of International Health, Baltimore, USA

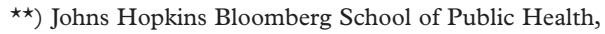
Department of Mental Health, Baltimore, USA

$\star \star \star)$ Fordham University, New York, USA

$\star \star \star \star)$ The University of Macau, Faculty of Social

Sciences, Department of Psychology, Macau (SAR), People's Republic of China
}

Correspondence to: pbolton1@jhu.edu tions for interventions that demonstrate effectiveness in treating survivors of torture and other systematic violence who suffer from PTSD, depression and anxiety. Priorities for mental health research for survivors of torture and other systematic violence are also recommended.

Keywords: torture, mental health, stress disorders, post-traumatic, depression, anxiety, outcome assessment.

\section{Introduction}

Torture has been documented in over 150 countries but its true incidence is difficult to document as victims may die from injuries incurred by torture and survivors often do not report incidents of torture. ${ }^{1}$ The torture experience among affected populations, such as refugees, migrant workers, and prisoners, varies widely with reports ranging from $3 \%$ of Bhutanese refugees in Nepal, to $36 \%$ of Somali refugees in the US, to $85 \%$ of detainees in Turkish prisons. ${ }^{1}$ As a particularly severe and varied form of both emotional and physical trauma, torture results in a variety of chronic and multidimensional sequelae. ${ }^{2-4}$ Torture survivors are more likely 
than individuals exposed to other forms of violence to report symptoms of posttraumatic stress disorder (PTSD), major depression, and elevated anxiety, and these symptoms often have severe consequences for daily functioning long after the events that precipitated them. ${ }^{5-11}$ Other mental health problems include substance abuse ${ }^{12}$ and less well-defined constructs such as long-term personality change. ${ }^{13}$ Although less common in the torture treatment literature, it is also clear that torture survivors suffer from significant physical problems as well. Long-term injuries are common, affecting survivors directly through physical impairment ${ }^{14,15}$ and indirectly by prolonging the effects of PTSD and depression. ${ }^{16}$ As a result, many treatment programs include medical care and physiotherapy. Although less studied within torture survivor populations, traumatic brain injury (TBI) and its neuropathological sequelae have been documented among torture survivors ${ }^{17}$ and evidence suggests that the prevalence of TBI is nontrivial among survivors seeking treatment. ${ }^{18}$

In addition to the direct effects of emotional and physical trauma, torture survivors often report substantial financial and social problems. This is especially true for those who flee their home regions in fear of re-victimization. For those seeking refugee status in another country, legal status, language ability, family separation and social isolation in general are often cited as common stressors. ${ }^{19}$ There is evidence to show that addressing these psychosocial problems may reduce symptoms of anxiety and depression. ${ }^{20}$ Those who are displaced within their own country are also likely to face stressors that cause substantial distress. Many torture treatment programs and the agencies that fund them make resolving such 'psychosocial stressors' a central feature of proposed interventions for torture survi- vors. ${ }^{21,22}$ In addition, many programs have begun to introduce livelihood programs that address the financial challenges torture survivors often face.

A publication from July 2012 by McFarlane and Kaplan presented a review of mental health interventions for adult survivors of torture and trauma; the authors defined survivors of torture and trauma as refugees, asylum seekers who apply to be recognized as refugees, displaced persons, and people living in their country of origin who have suffered persecution and gross human rights violations. ${ }^{23}$ The McFarlane review identified 40 studies published from 1980 to 2010 including 11 randomized controlled trials (RCTs), eight with non-random comparison groups, and 21 single cohort before and after studies. The review found that interventions were largely effective in improving mental health symptoms. Only four out of the 40 studies they identified did not show any significant improvement post-intervention for at least one outcome indicator. They also noted a bias for studying PTSD symptoms in survivors over other outcomes such as depression and anxiety. Additionally, treatment outcomes were affected by time. Most studies showed treatment effects lasting from three to 18 months; studies in which treatment effects were lost after two to three years may have been affected by ongoing insecurity.

McFarlane and Kaplan used the previously developed Quality Assessment Tool to rate the methodological quality of the studies with RCTs having the strongest ratings, followed by studies that used non-random comparisons and finally single cohort studies. ${ }^{24}$ The review, along with their mention of a recent meta-analysis, ${ }^{25}$ found that Narrative Exposure Therapy (NET) and Cognitive Behavioral Therapy (CBT) had moderate and cautious support as effective 
treatments among refugees and asylum seekers, including several RCTs, while also noting that these studies had not been replicated sufficiently outside a small group of researchers. ${ }^{25}$ While McFarlane and Kaplan did not consider it feasible to include case studies in their review, we found that case studies were, along with other observational studies, the most frequently used study design, and we chose to include them in our review. We believe this is an important addition as it may indicate potentially promising interventions that require further study, but that may have been missed by the search methods used in McFarlane and Kaplan. In addition, our review included 16 studies published after 2010 that were not included in the McFarlane and Kaplan review. We also used different search syntax that identified additional studies. Instead of rating the methodological quality of the studies as did McFarlane and Kaplan, we chose to classify each intervention arm within the studies separately by the study design used (described below). This provided an opportunity for a more granular analysis of the impact of specific interventions if studies had several intervention arms.

\section{Purpose}

The primary purpose of this research was to clarify the evidence, as of March 2014, concerning the effectiveness of mental health interventions for survivors of torture and systematic violence. In doing so, we want to encourage and enable practitioners to use evidence-based therapies until such time as other therapies have developed a sufficient evidence base. Our secondary purpose was to recommend priorities for research from the mental health interventions that show promise but, as of the date of writing, do not have sufficient evidence for recommending implementation in the field.

\section{Methods}

Overview of the review and analysis

The review was carried out by faculty and students at the Johns Hopkins Bloomberg School of Public Health for the Victims of Torture Fund (VOT) at the United States Agency for International Development (USAID). Work on the review began in September 2008 and was completed in March 2014. The literature review and analysis included peer-reviewed journal articles describing mental health studies that included victims of torture and other systematic violence as study participants. One criterion for inclusion in the review was that articles provide original evidence referring to the effectiveness of interventions, regardless of the strength of evidence. This criterion led us to exclude review articles unless the review article contained information about a study that we could not obtain and review directly. Review articles also were an important source for identifying original research. Another inclusion criterion was that the study population (at least in part) was exposed to torture or systematic violence by organized groups (including war and refugees from war). We excluded studies whose participants were solely victims of accidents or random and isolated acts of violence, studies where children were the only participants, and studies not published in English.

The research used the following search engines to identify articles for screening and review: PubMed, PsychINFO, Web of Science EMBASE, Scopus, and Global Health. Four comprehensive search strings were created and combined to use with these search engines. These strings - or groups of words - utilized mental health terms, torture terms, intervention terms, and effectiveness terms (Table 1).

The interventions included in each study were classified as to the strength or level of their evidence. For example, an intervention 
Table 1: Search strings used in literature search for the Intervention Database

\begin{tabular}{|c|c|}
\hline Concept & Terms \\
\hline Mental health & $\begin{array}{l}\text { mental health OR mental disorder OR mental disorders OR mental illness } \\
\text { OR mental illnesses OR mental disease OR mental diseases OR anxiety OR } \\
\text { depression OR depressive OR ptsd OR post-traumatic stress OR post } \\
\text { traumatic stress OR posttraumatic stress OR stress OR distress OR trauma } \\
\text { OR traumatic OR panic disorder OR panic disorders OR mood disorder OR } \\
\text { mood disorders }\end{array}$ \\
\hline
\end{tabular}

Torture $\quad$ torture OR tortures OR (("human rights" OR prisoner OR prisoners OR systemic OR systemically OR systematic OR systematically) AND (abuse OR abuses $\mathrm{OR}$ abuse $\mathrm{OR}$ violation $\mathrm{OR}$ violations $\mathrm{OR}$ violated $\mathrm{OR}$ punish $\mathrm{OR}$ punishment OR punished))

Intervention intervention OR interventions OR treatment OR treatments OR therapy OR therapies $\mathrm{OR}$ therapeutic $\mathrm{OR}$ rehabilitation $\mathrm{OR}$ program $\mathrm{OR}$ programs $\mathrm{OR}$ psychotherapy OR psychotherapeutic OR psychoeducation OR counseling OR psychosocial

Effectiveness effectiveness OR effective OR efficacy OR efficacious OR impact OR impacts OR outcome OR outcomes OR assessment OR improvement OR ineffective OR ineffectiveness OR detrimental OR limited

tested in a randomized controlled trial (RCT) was considered to have stronger evidence for effectiveness than a study with a comparison group that was selected purposively or by convenience, or a study with no comparison group at all. ${ }^{\mathrm{i}}$ Studies were coded in part by graduate students (who conducted the literature search and coded the type of evidence and results) and in part by $\mathrm{PhD}$ trained clinical psychologists (who specifically coded all treatment-and diagnosticrelated variables using a therapy codebook written for this database).

\footnotetext{
${ }^{\mathrm{i}}$ If participants in a study were randomized to one of two interventions but there was no control group (e.g., wait list control, treatment as usual), then the study's interventions were classified as a pre-and post-test measurement of impact in the evidence column. This was due to the results allowing only for a comparison of outcomes between different interventions, but without understanding the counterfactual---what would have happened without the interventions---which requires a true control group.
}

\section{Analytic Procedure}

We classified the mental health interventions in our database as (1) effective for addressing key mental health problems, (2) promising, (3) unclear, or (4) ineffective. An intervention was classified as effective if there was evidence of improvement in symptoms across multiple randomized control trials that were carried out by more than one investigation team. An intervention was classified as promising if there was evidence of the following: (1) consistent improvement in symptoms but the number of RCTs was small; (2) consistent improvement in symptoms but only among RCTs carried out by investigators that are not independent of each other (need for independent confirmation); or (3) no randomized trials, but other less rigorous studies consistently showing improvements. An intervention was classified as unclear if there was a lack of consistency in the direction of the findings (e.g., some resulted in improvement in symptoms 
but some did not, or there were very few studies). A classification of ineffective was given to an intervention if the majority of studies of that intervention demonstrated no improvements in symptoms.

We used Tableau Desktop 8.2 software (Tableau Software, Seattle, WA) for analysis and visualization of the data. We graphed the number of interventions included in the studies by region, country, type of therapy, symptoms or problems targeted by the interventions, and findings of the interventions by the strength or level of evidence.

\section{Results}

The literature review included 88 studies of interventions for victims of torture and systematic violence. ${ }^{26-114}$ Most studies of interventions for survivors of torture and other systematic violence were conducted in Europe (44\%). The remaining studies were conducted in the United States (32\%), Africa (12\%), Asia (7\%), Middle East (3\%), and Latin America (2\%). We identified only a few research studies from Eastern Europe and only two Latin American studies.

Figure 1: Location of studies by country 
Mental health interventions in the literature review studies

The number of intervention arms or therapies tested (102) was greater than the number of studies listed; the 88 studies often included more than one intervention. For example, a 2008 randomized trial reported by Alder et al. included the following two intervention arms: critical incident stress debriefing; and a stress management class. ${ }^{114}$

For ease of summarization, we grouped the intervention arms into types of therapies - therapies with similar theoretical bases (Figure 2). Cognitive behavioral and psychosocial therapies were the most frequently studied types of therapies (37 and 19 out of 102 intervention arms, respectively), followed by multi-disciplinary (defined as one or more therapies plus pharmacotherapy, 18 arms), holistic (10 arms), pharmacotherapy alone ( 9 arms), multi-therapy (two or more therapies of different families excluding pharmacotherapy, 5 arms), psychodynamic (3 arms), and interpersonal (1 arm). ${ }^{\text {ii Since }}$ CBT is such a broad classification, we differentiated multiple therapies within CBT such as CBT with exposure, $\mathrm{CBT}$ without exposure, CBT with panic elements, and testimonial. We further differentiated CBT-based treatments that are manualized and have their own line of research, such as NET.

\section{Symptoms and issues targeted by the interventions}

PTSD was the most frequently targeted disorder or issue among the mental health

\footnotetext{
ii Holistic therapies were defined as treatments outside conventional psychotherapy/medicine and are also known as complimentary or alternative medicine (CAM). Many of these treatments have non-Western origins and most emphasize a strong "mind-body" connection.
}

intervention arms in the review (78 of 102 intervention arms; Figure 3). After PTSD, depression ( 55 intervention arms) and anxiety (36 arms) were the most frequently targeted problems. Functioning was targeted in 15 intervention arms. Relatively few intervention arms sought to address pain (12 arms), panic attacks (6 arms), and substance abuse (1 arm). Forty-two intervention arms addressed a number of additional symptoms (i.e. sleep problems), but no specific symptom in any substantial numbers.

\section{Level of evidence provided for inter- ventions in the Intervention Database}

Of the 102 intervention arms in the review, 42 intervention arms were compared to another intervention arm and/or a control arm. The control arm was typically a wait list control or treatment as usual. Among the 42 intervention arms with a comparison group, 30 participants were assigned using a randomization process; in the other twelve intervention arms, participants were assigned using a non-random process (purposive or convenience). Of the 30 intervention arms to which participants were assigned randomly, some (12 arms) did not include a comparison group that could act as a true control or counterfactual as to what would have happened to clients without an intervention. For example, Paunovic and Ost randomized participants to receive either CBT with exposure, or exposure-only therapy; there was no control or placebo arm, or evidence-based standard of care, to act as a counterfactual. ${ }^{95}$ In these 12 cases, we classified the level of evidence of the intervention arms as a preand post-test measurement of impact rather than an RCT. The rationale for this classification is that most studies recruited participants based on severity of symptoms, diagnoses, or care-seeking behavior. 
Figure 2: Number of intervention arms by type of therapy

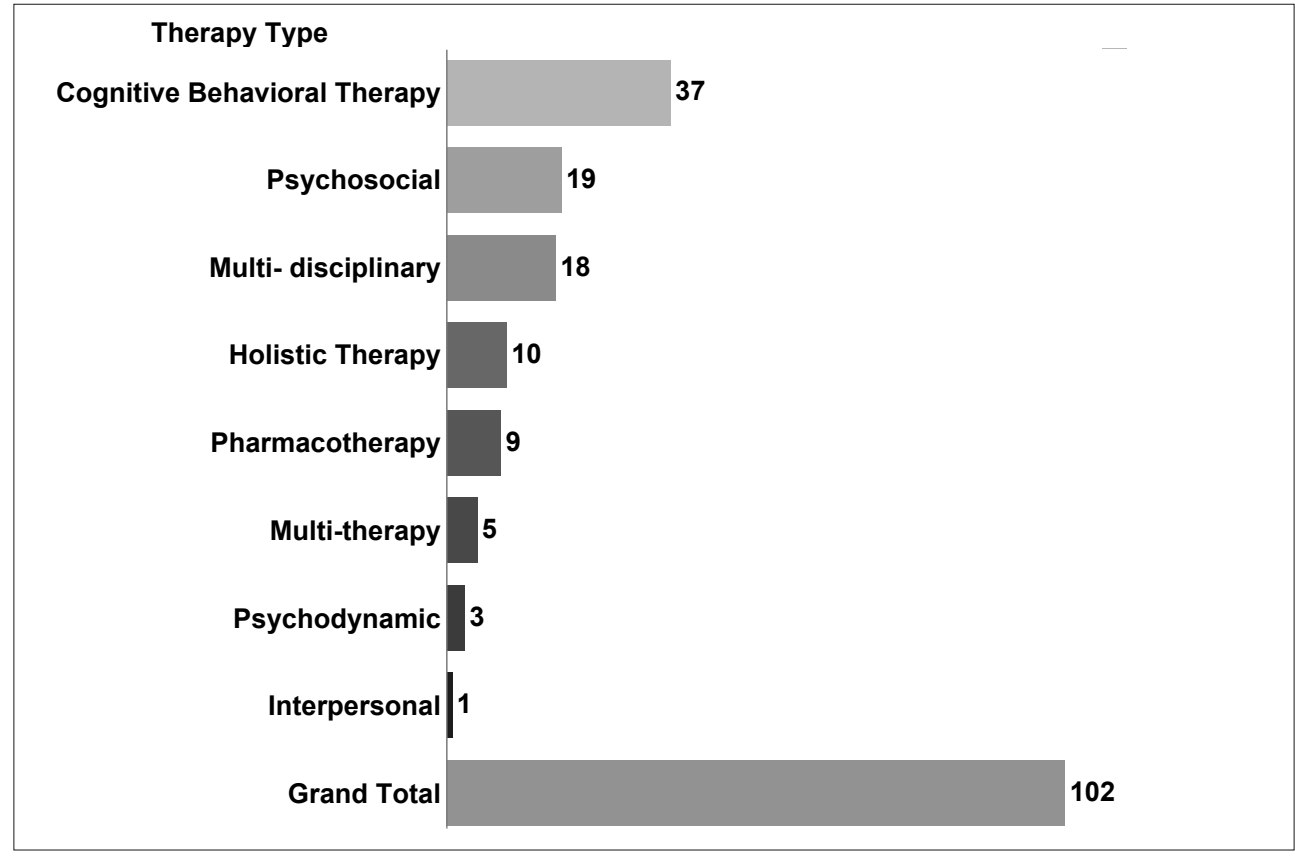

Figure 3: Number of intervention arms by symptom targeted

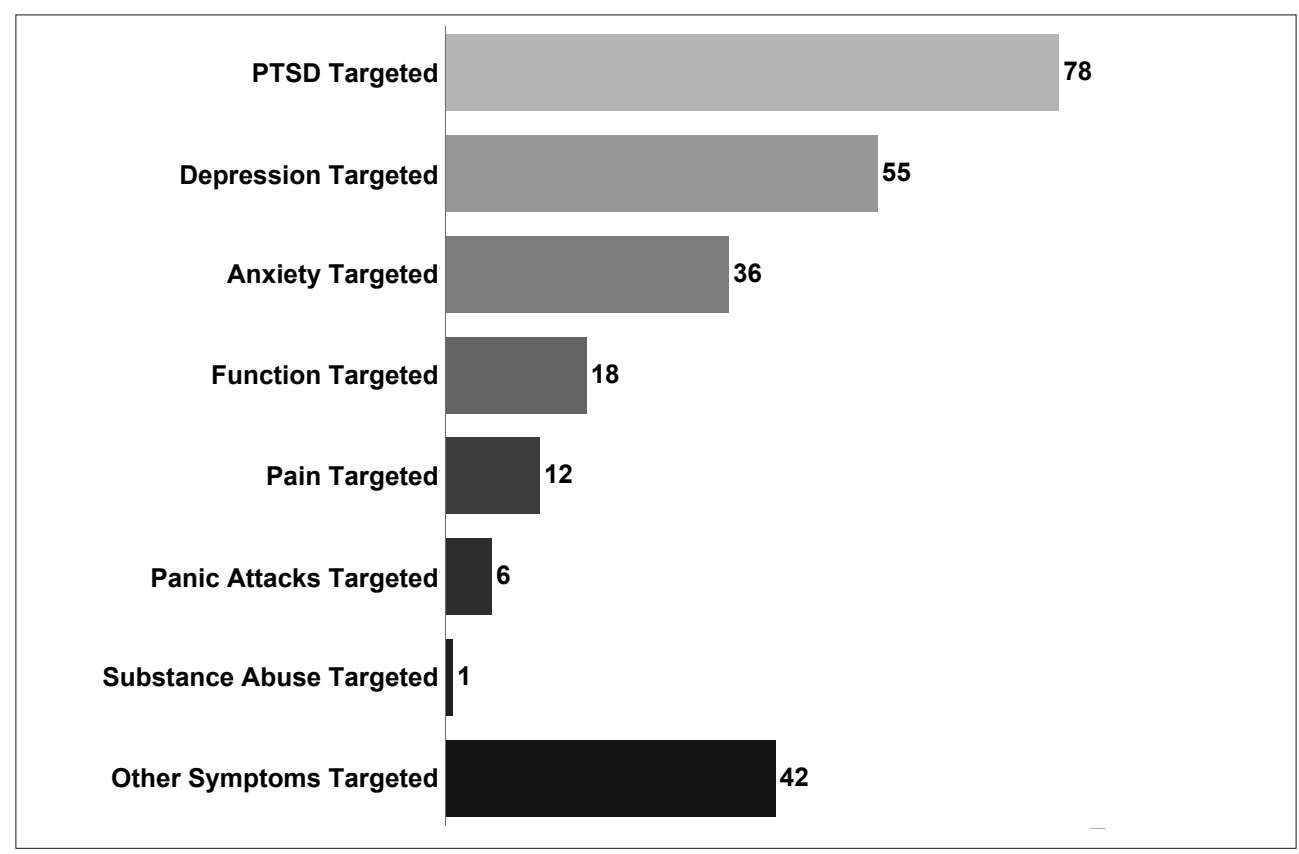


There will be a tendency for severe symptoms to become less severe over time even with no intervention (the concept of regression to the mean). Therefore, improvement of symptoms among intervention participants, without a relative comparison to the changes experienced by a control group, is a lower level of evidence of the effectiveness of an intervention compared to an RCT.

Among the 60 intervention arms that did not include a comparison group, the level of evidence for the majority (49 arms) was a pre- and post-test measurement of impact. Five interventions included only a post-test measurement, and 18 provided only anecdotal reports of impact (measure of change based on observations of a few clients). In all interventions, symptoms were measured with structured diagnostic interviews (e.g.,
Mini International Neuropsychiatric Interview; MINI), questionnaires (e.g., Hopkins Symptom Checklist-25; HSCL-25), both structured diagnostic interviews and questionnaires, or by other methods (i.e., informal interviews). ${ }^{115,116}$

\section{Effectiveness of interventions for PTSD symptoms among adult survivors of torture and other systematic violence}

Summary: CBT with exposure components has sufficient evidence at this time to recommend use by NGO programs to address PTSD. Promising interventions that are currently recommended for priority research among adult survivors of torture and other systematic violence with PTSD are the following: Narrative Exposure Therapy (NET); Interpersonal Therapy (IPT); Pharmacotherapy (alone); and,

Figure 4: Number of intervention arms targeting PTSD by type of therapy, type of evidence and impact

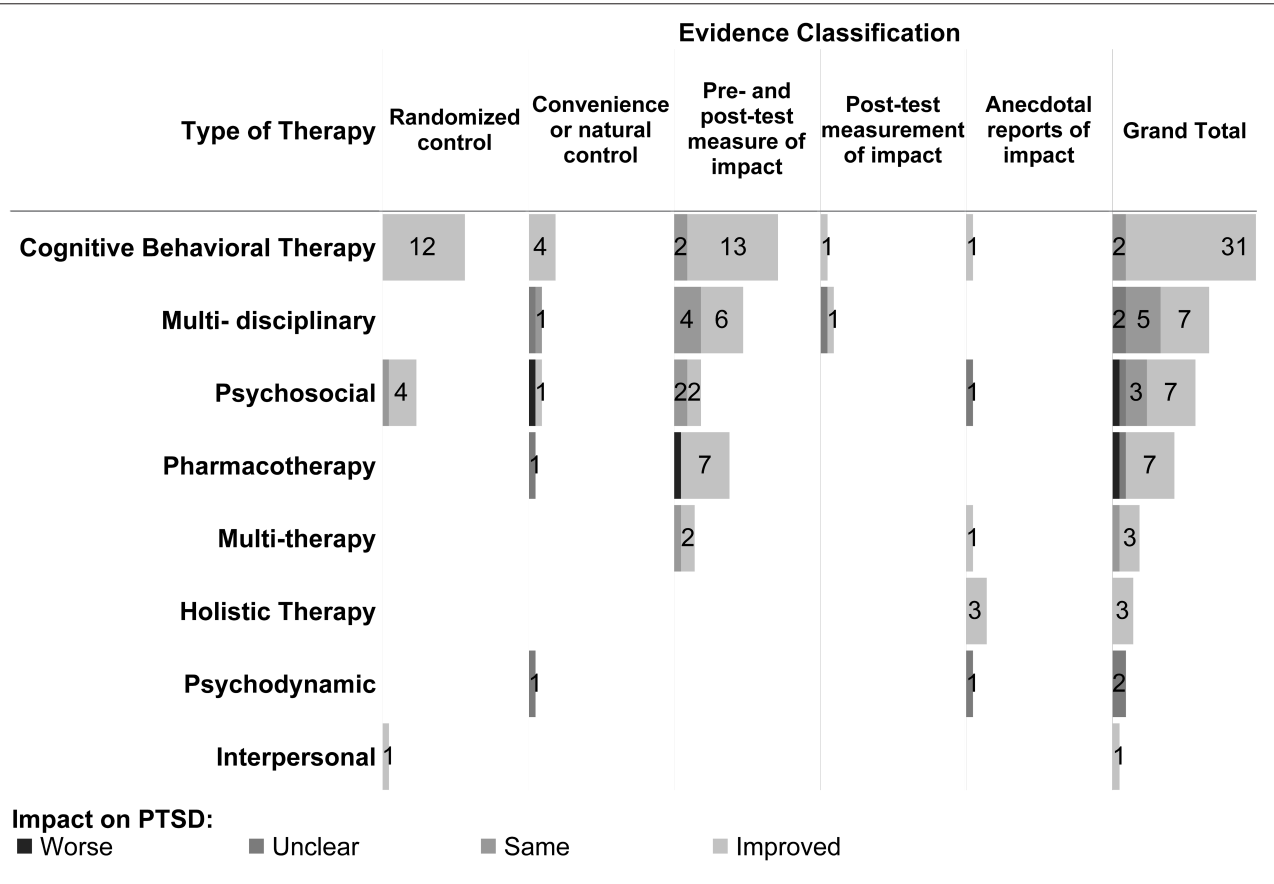


Multi-disciplinary therapies (many with CBT and pharmacotherapy components).

Seventy-eight of 102 intervention arms in the review targeted PTSD symptoms. PTSD symptoms were measured with structured diagnostic interviews (17), questionnaires (37), both structured diagnostic interviews and questionnaires (13), or by other methods (9); two intervention arms did not report any type of assessment method. Intervention arms that appear to be effective in addressing PTSD among survivors of torture and other systematic violence belonged to the CBT types of therapies (Figure 4), based on positive findings from multiple RCTs carried out by investigators independent from one another.

The following interventions show promise: NET and Testimonial Therapy or TT, IPT, pharmacotherapy (alone), multidisciplinary therapies (many with CBT and pharmacotherapy components), and multi-therapy (many with CBT). However, the evidence available for these interventions was primarily from one group of investigators (NET), a small number of RCTs (IPT), or primarily from pre-and post-test measures of impact rather than controlled trials.

Among the CBT group of therapies, 31 of $33(94 \%)$ intervention arms resulted in reduction of PTSD symptoms. ${ }^{29}, 32,39,51,58,60$, $61,63,64,67,75,79,85,95,100,101,105,110$ CBT with trauma exposure components (e.g., having the client remember and tell a detailed story about their trauma until habituation occurs) had the most evidence of effectiveness (Figure 5). All CBT interventions that involved

Figure 5: Number of intervention arms targeting PTSD among CBT types of therapies by type of evidence and impact

\section{Evidence Classification}

\begin{tabular}{|c|c|c|c|c|c|c|}
\hline Intervention Arm & $\begin{array}{c}\text { Randomized } \\
\text { control }\end{array}$ & $\begin{array}{l}\text { Convenience } \\
\text { or natural } \\
\text { control }\end{array}$ & $\begin{array}{l}\text { Pre- and } \\
\text { post-test } \\
\text { measure of } \\
\text { impact }\end{array}$ & $\begin{array}{c}\text { Post-test } \\
\text { measurement } \\
\text { of impact }\end{array}$ & $\begin{array}{l}\text { Anecdotal } \\
\text { reports of } \\
\text { impact }\end{array}$ & Grand Total \\
\hline CBT (with exposure) & 3 & & 3 & 1 & & 7 \\
\hline CBT (not including exposure) & 1 & 1 & & & & 2 \\
\hline Cognitive processing therapy (with interpreter) & & 1 & 1 & & & 2 \\
\hline Exposure only therapy & & & 2 & & & 2 \\
\hline CBT Biofeedback & 1 & & 1 & & & 11 \\
\hline Stress inoculation training & & 1 & 1 & & & 11 \\
\hline CBT (with panic exposure) & 1 & & & & & 1 \\
\hline $\mathrm{CBT}$ (with trauma and panic exposure) & & & 1 & & & 1 \\
\hline CBT Biofeedback + physical activity & 1 & & & & & 1 \\
\hline Cognitive processing therapy (w/o interpreter) & & 1 & & & & 1 \\
\hline Narrative Exposure Therapy & 4 & & 5 & & & 9 \\
\hline Testimonial Therapy & 1 & & 1 & & 1 & 3 \\
\hline $\begin{array}{l}\text { Impact on PTSD: } \\
\square \text { Same }\end{array}$ & & & & & & \\
\hline
\end{tabular}


Figure 6: Number of intervention arms targeting PTSD among Psychosocial therapies by type of evidence and impact

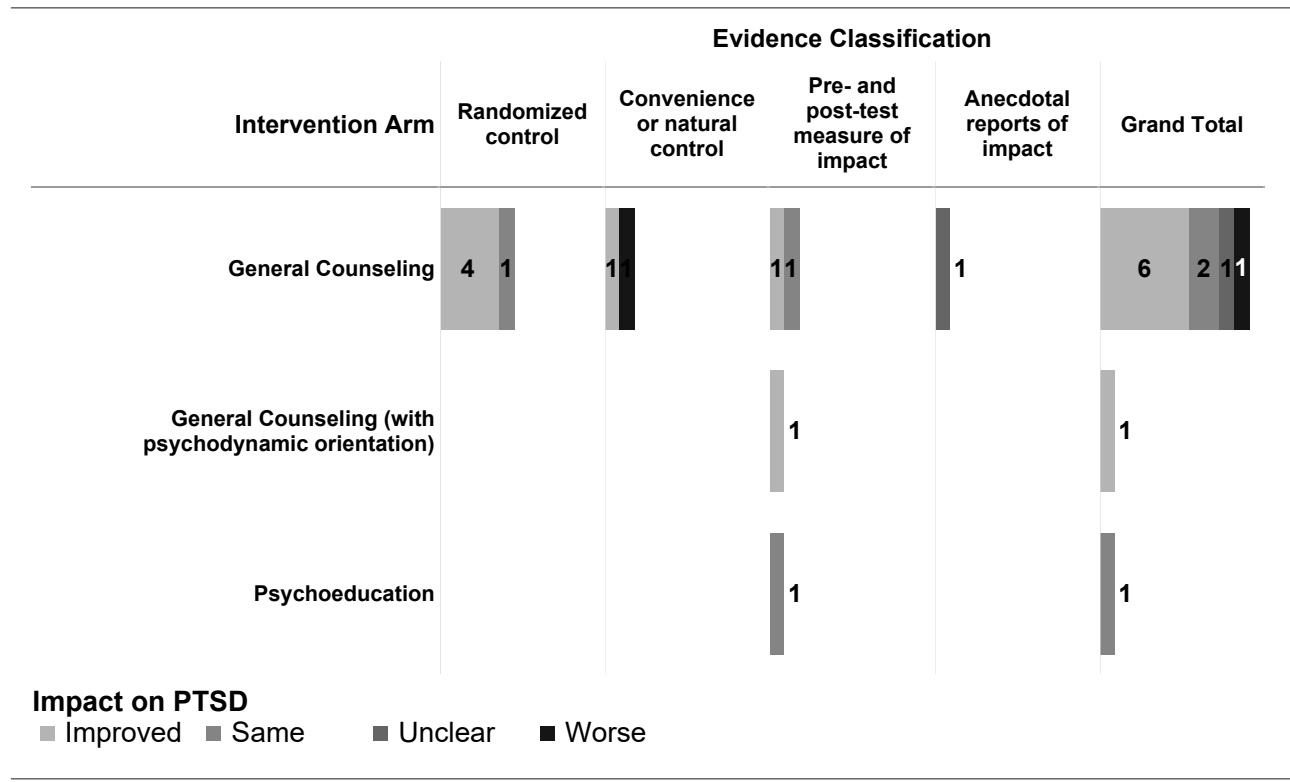

trauma exposure showed reduction in PTSD symptoms, including two RCTs. Promising interventions - those with improved PTSD symptoms but without the level of evidence of several or more RCTs from independent investigators - included the following: NET, TT, CBT with panic exposure, CBT with biofeedback and physical activity, CBT without exposure, cognitive processing therapy, and exposure-only therapy. For example, all nine NET intervention arms, carried out by a single group of investigators, showed improvement in PTSD symptoms.

The evidence for the psychosocial type of therapies on symptoms of PTSD was mixed, with some intervention arms resulting in improved symptoms while other intervention arms had no effect or worsened symptoms (Figure 6). With respect to the five RCT intervention arms targeting PTSD among the psychosocial group of therapies in the database, four demonstrated improvement in
PTSD symptoms while one yielded no significant effect in either direction. ${ }^{48,88,89}$, ${ }^{113}$ Two of the four psychosocial interventions with pre- and post-test measures of impact (no control group) as evidence showed improvement. ${ }^{65,107}$

Pharmacotherapy, multi-disciplinary, and multi-therapy types of interventions also show promise in ameliorating symptoms of trauma. Studies of all three types of therapies documented improvements in trauma symptoms using a pre- and post-test measurement design. Pharmacotherapies included medications typically used to treat symptoms of anxiety, depression, and trauma. Medications included selective serotonin reuptake inhibitors (SSRIs; e.g., Sertraline), tri-cyclic antidepressants (e.g., Imipramine), serotoninnorepinephrine reuptake inhibitors (e.g., Venlafaxine), alpha-andrenergic blockers (e.g., Prazosin), adrenergic agonists (e.g., Clonidine), and anxiolytics (e.g., Diazepam). 
Figure 7: Number of Multi-Disciplinary $\mathcal{E}$ Multi-Therapy intervention arms targeting PTSD by type of evidence and impact

\begin{tabular}{|c|c|c|c|c|c|c|}
\hline \multirow[b]{2}{*}{$\begin{array}{l}\text { Therapy } \\
\text { Type }\end{array}$} & \multirow[b]{2}{*}{ Intervention Arm } & \multicolumn{5}{|c|}{ Evidence Classification } \\
\hline & & $\begin{array}{l}\text { Convenience } \\
\text { or natural } \\
\text { control }\end{array}$ & $\begin{array}{c}\text { Pre- and } \\
\text { post-test } \\
\text { measure of } \\
\text { impact }\end{array}$ & $\begin{array}{l}\text { Post-test } \\
\text { measurement } \\
\text { of impact }\end{array}$ & $\begin{array}{c}\text { Anecdotal } \\
\text { reports of } \\
\text { impact }\end{array}$ & Grand Total \\
\hline \multirow{12}{*}{$\begin{array}{l}\text { Multi- } \\
\text { disciplinary }\end{array}$} & Pharmacotherapy, general counseling & & 2 & 1 & & $\begin{array}{ll}1 & 2\end{array}$ \\
\hline & CBT + Pharmacotherapy & & 1 & & & 1 \\
\hline & EMDR + CBT + Relaxation + Pharmacotherapy + Psychodynamic & & 1 & & & 1 \\
\hline & General Counseling + physiotherapy + Social counseling & & 1 & & & 1 \\
\hline & General Counseling and Pharmacotherapy & & 1 & & & 1 \\
\hline & Pharmacotherapy + CBT & & 1 & & & 1 \\
\hline & Pharmacotherapy + Group Psychodynamic Therapy & 1 & & & & 1 \\
\hline & Pharmacotherapy and/or Holistic and/or General Counseling & & 1 & & & 1 \\
\hline & Physiotherapy, pharmacotherapy, general counseling, testimonial & & & 1 & & 1 \\
\hline & Physiotherapy, general counseling, pharmacotherapy & & 1 & & & 1 \\
\hline & Physiotherapy, pharmacotherapy, CBT (with exposure), EMDR & & 1 & & & 1 \\
\hline & Physiotherapy, pharmacotherapy, general counseling, legal services & 1 & & & & 1 \\
\hline \multirow{4}{*}{$\begin{array}{l}\text { Multi- } \\
\text { therapy }\end{array}$} & Biofeedback + NET & & 1 & & & 1 \\
\hline & $\mathrm{CBT}$ (with exposure) + Testimonial Therapy & & 1 & & & 1 \\
\hline & CBT EMDR + Thought Field Therapy & & & & 1 & 1 \\
\hline & Psychodynamic + CBT + Gestalt + Systemic & & 1 & & & 1 \\
\hline $\begin{array}{l}\text { Impact on P } \\
\text { Unclear }\end{array}$ & Improved & & & & & \\
\hline
\end{tabular}

For the multi-disciplinary and multitherapy types of therapies, those that showed improvement in PTSD symptoms (primarily studies with pre- and post-test measurements) included a mix of the following components: pharmacotherapy, general counseling, CBT, TT and physiotherapy (see Figure 7). 34-36, 38, 41, 42, 47, 54, 62, 71, 80, 84, 92-94, 97, 103, 108 However, several of the same components were also included in multi-disciplinary and multi-therapy therapies that did not result in reductions in PTSD symptoms: pharmacotherapy, general counseling, and physiotherapy. Most multi-disciplinary and multi-therapy therapies that documented reductions in PTSD symptoms included the components of CBT, TT, or pharmacotherapy. However, it is not possible to determine which component(s) were responsible for the effect given the designs of available studies.

All three intervention arms among the holistic types of therapies that targeted PTSD demonstrated reductions in PTSD symptoms, but the type of evidence for all of these interventions was anecdotal and should therefore be interpreted cautiously. ${ }^{55,68,96}$ The effectiveness of psychodynamic therapies was unclear; unclear was defined as a situation in which the coder was unable to determine, from the content of the article, the results of the study regarding the symptom in question (PTSD in this particular case).

Effectiveness of interventions for depression symptoms among adult survivors of torture and other systematic violence

Summary: As with interventions that address PTSD, CBT with exposure components has sufficient evidence at this time to recommend use by NGO programs targeting depression symptoms among adult survivors of torture and 
other systematic violence. Promising interventions that are currently recommended for priority research with respect to depression are the same as with those addressing PTSD: Narrative Exposure Therapy (NET); Interpersonal Therapy (IPT); Pharmacotherapy (alone); Multi-disciplinary therapies (many with CBT and pharmacotherapy components).

Fifty-five intervention arms in the review targeted depression symptoms. Depression symptoms were measured with structured diagnostic interviews, ${ }^{2}$ questionnaires, ${ }^{37}$ both structured diagnostic interviews and questionnaires, ${ }^{5}$ or by other methods ${ }^{8}$; three intervention arms did not report any type of assessment method. The most effective intervention arms for improving depression among survivors of torture and other systematic violence were from the CBT group of therapies (Figure 8). Nineteen of 23 CBT intervention arms reported reduced depression symptoms, including six of seven randomized trials, 11 of 14 pre- and post-test measures, and two of two post-test measure of impact. $^{29,} 32,39,51,58,60,63,64,67,85,95,110$ Among CBT intervention arms, 20 of the 23 intervention arms included exposure; 18 of these intervention arms (including five RCTs) reported reduced depression symptoms. Neither the one intervention arm of CBT with biofeedback, nor the one intervention arm of stress inoculation training resulted in improvements in depression. ${ }^{58,85}$ The two intervention arms that showed no improvement were both NET interventions, one of which was an RCT. $^{58,89}$

Only one of nine intervention arms among the psychosocial group of therapies showed a reduction in depression (Figure 9). This was an Empowerment Workshop. ${ }^{98}$ However, another intervention arm of the Empowerment Workshop, among the nine, documented

Figure 8: Number of intervention arms targeting depression by type of therapy, level of evidence, and impact

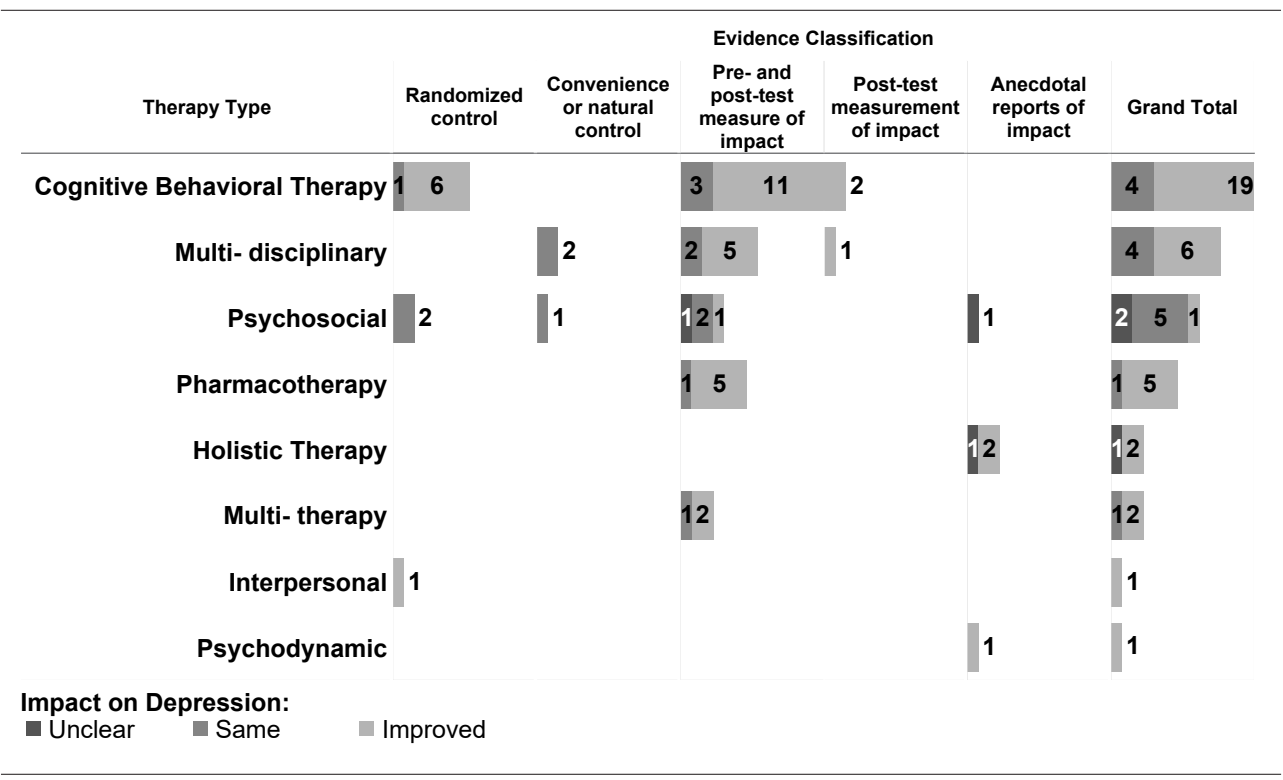


Figure 9: Number of intervention arms targeting depression among interpersonal and psychosocial therapies by type of evidence and impact

\begin{tabular}{|c|c|c|c|c|c|c|}
\hline \multirow[b]{2}{*}{$\begin{array}{l}\text { Type of } \\
\text { Therapy }\end{array}$} & \multirow[b]{2}{*}{ Intervention Arm } & \multicolumn{5}{|c|}{ Evidence Classification } \\
\hline & & $\begin{array}{l}\text { Randomized } \\
\text { control }\end{array}$ & $\begin{array}{l}\text { Convenience or } \\
\text { natural control }\end{array}$ & $\begin{array}{c}\text { Pre- and } \\
\text { post-test } \\
\text { measure of } \\
\text { impact }\end{array}$ & $\begin{array}{l}\text { Anecdotal } \\
\text { reports of } \\
\text { impact }\end{array}$ & Grand Total \\
\hline Psychosocial & General Counseling & 2 & 1 & 1 & 1 & 3 \\
\hline & Empowerment workshop & & & 1 & & 11 \\
\hline & Psychoeducation & & & 1 & & 1 \\
\hline Interpersonal & $\begin{array}{l}\text { Interpersonal } \\
\text { psychotherapy }\end{array}$ & 1 & & & & 1 \\
\hline $\begin{array}{l}\text { Impact on D } \\
\text { Unclear }\end{array}$ & $\begin{array}{l}\text { Depression: } \\
\text { Same }\end{array}$ & ved & & & & \\
\hline
\end{tabular}

no improvement. ${ }^{45}$ The study design for both of these Empowerment Workshops was a pre- and post-test measurement of impact. There were two intervention arms from the psychosocial group that used an RCT study design (a general counseling arm and a stress management class arm) and neither showed improvement in depression symptoms. ${ }^{48,89}$ Two general counseling intervention arms (one pre- and post-measure, and one anecdotal report) provided results that were unclear to those persons coding the studies for the literature review. ${ }^{70,107}$

There was only one intervention arm using Interpersonal Therapy (IPT): it was a randomized controlled trial, and it resulted in a reduction in depression symptoms. ${ }^{82}$

Five of six pharmacotherapy (alone) intervention arms documented improved depression symptoms. ${ }^{30,72,93,104}$ These were all intervention arms with a pre- and post-test measurement design only. Six of ten intervention arms among the multi-disciplinary type of therapies documented improved depression symptoms. Of these six, five had a pre- and post-test measurement design, and one had a post-test only design; all six intervention arms included pharmacotherapy components. ${ }^{35,36,71,83,93,94}$ There was only one multi-disciplinary intervention arm that included a comparison group (a convenience control); this intervention arm did not result in reductions in depression symptoms. ${ }^{112}$ The components in this intervention arm included physiotherapy, pharmacotherapy, general counseling, and legal services.

Three intervention arms among the Holistic Therapy group of therapies addressed depression. ${ }^{40,53,74}$ All three were dance/movement intervention arms and provided anecdotal reports of impact. Two documented improved depression symptoms. ${ }^{40,53}$ The one intervention arm among 
the psychodynamic therapies (Yalom Group Psychotherapy) showed a reduction in depression symptoms, but this was an anecdotal report. ${ }^{91}$

\section{Effectiveness of interventions for anxi-} ety symptoms among adult survivors of torture and other systematic violence

Summary: Among interventions for adult survivors of torture and other systematic violence that address anxiety symptoms, $C B T$ with exposure components has sufficient evidence at this time to recommend use by NGO programs. Promising interventions that are currently recommended for priority research among adult survivors of torture and other systematic violence with anxiety are the following: Cognitive Behavioral Therapy with biofeedback and pharmacotherapy (alone).
Thirty-six intervention arms in the Intervention Database targeted anxiety symptoms. Anxiety symptoms were measured with structured diagnostic interviews (3), questionnaires (24), both structured diagnostic interviews and questionnaires (5), or by other methods (3); one intervention arm did not have any type of assessment method documented.

Intervention arms from the CBT type of therapies appear to be most effective for treating anxiety symptoms among survivors of torture and other systematic violence (Figure 10). Of 16 CBT intervention arms targeting anxiety, 12 resulted in improved anxiety symptoms and five of these 12 were

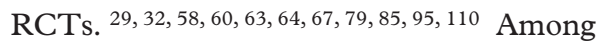
the 16 intervention arms within the CBT group of therapies, CBT with exposure had the most evidence for effectiveness (Figure

Figure 10: Number of intervention arms targeting anxiety by type of therapy, type of evidence and impact

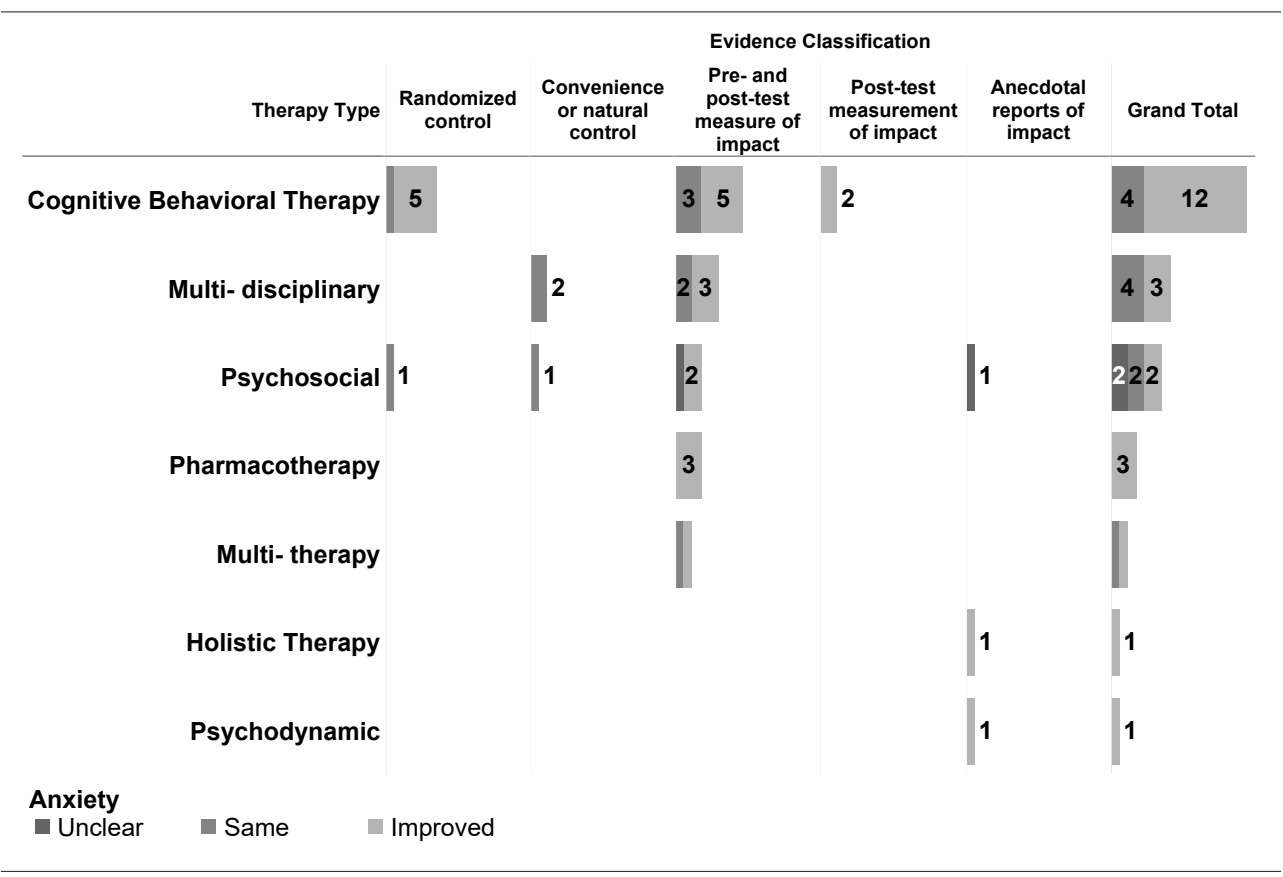


Figure 11: Number of CBT intervention arms targeting anxiety by type of evidence and impact

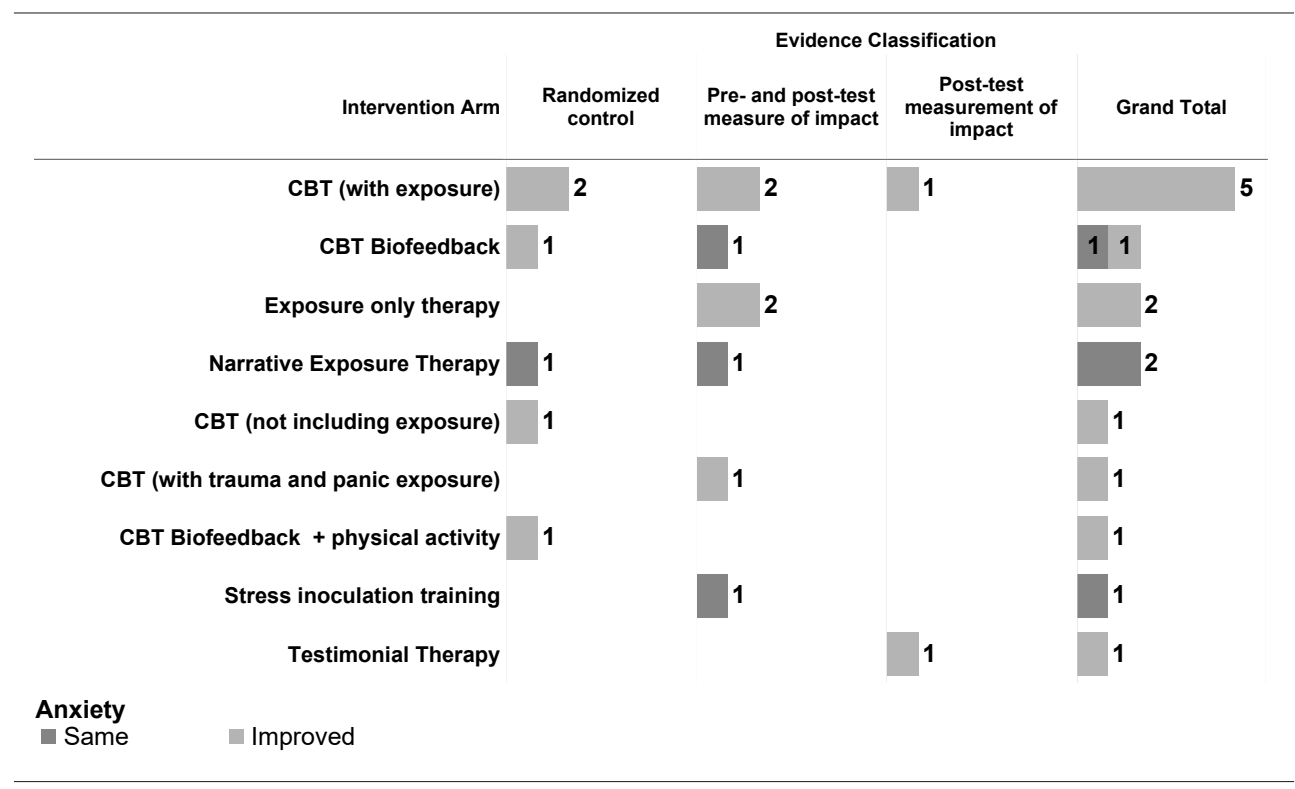

11). Nine of $11 \mathrm{CBT}$ intervention arms that included a component of exposure resulted

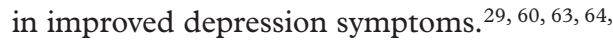
67, 95, 110 Five of five 'CBT with exposure' intervention arms documented improved anxiety symptoms, and two of these five were

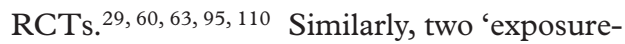
only therapy' intervention arms, both with pre- and post-test measure designs, documented reductions in anxiety symptoms. ${ }^{67,95}$ One intervention arm of ' $\mathrm{CBT}$ with trauma and panic exposure' (counted separately from the 'CBT with exposure' intervention arms described above) documented improvement in anxiety. ${ }^{64}$ One intervention arm of TT showed improvement in anxiety symptoms, but the level of evidence was a weaker post-test measurement. ${ }^{44}$ Two NET intervention arms (one RCT, one pre- and post-test measure) targeting anxiety did not document improvement in anxiety symptoms. ${ }^{58,89}$

Three other intervention arms among the CBT group with an RCT design showed improvement in anxiety: CBT not including exposure, CBT with biofeedback (only), and CBT with biofeedback and physical activity. ${ }^{32,79}$ Note that there was another intervention arm of CBT with biofeedback that showed no improvement in anxiety symptoms and this used a pre- and post-test measure design. ${ }^{85}$ One intervention arm of stress inoculation therapy, using a pre- and post-test design, showed no change in anxiety. ${ }^{58}$

Studies with a pharmacotherapy (alone) intervention arm for anxiety showed promise but require further research for survivors of torture and other systematic violence. All three of the pharmacotherapy (alone) intervention arms that targeted anxiety resulted in improvement, but the level of evidence of each was limited to a pre- and post-test study design. ${ }^{30,49,93}$

None of the seven multi-disciplinary intervention arms targeting anxiety included an RCT (Figure 12). The three 
Figure 12: Multi-Disciplinary and Psychosocial therapies targeting anxiety by intervention arm, type of evidence and impact

\begin{tabular}{|c|c|c|c|c|c|c|c|}
\hline \multirow[b]{2}{*}{ Type of Therapy } & \multirow[b]{2}{*}{ Intervention Arm } & \multicolumn{6}{|c|}{ Evidence Classification } \\
\hline & & $\begin{array}{l}\text { Randomized } \\
\text { control }\end{array}$ & $\begin{array}{l}\text { Convenience } \\
\text { or natural } \\
\text { control }\end{array}$ & $\begin{array}{c}\text { Pre- and } \\
\text { post-test } \\
\text { measure of } \\
\text { impact }\end{array}$ & $\begin{array}{c}\text { Anecdotal } \\
\text { reports of } \\
\text { impact }\end{array}$ & Grand & Total \\
\hline \multirow{7}{*}{$\begin{array}{l}\text { Multi- } \\
\text { disciplinary }\end{array}$} & Pharmacotherapy, general counseling & & & 1 & & 1 & \\
\hline & $\begin{array}{l}\text { Physiotherapy, pharmacotherapy, } \\
\text { CBT (with exposure), EMDR }\end{array}$ & & & 1 & & 1 & \\
\hline & CBT + Pharmacotherapy & & & 1 & & 1 & \\
\hline & $\begin{array}{l}\text { Physiotherapy, pharmacotherapy, } \\
\text { general counseling, legal services }\end{array}$ & & 1 & & & 1 & \\
\hline & $\begin{array}{l}\text { Physiotherapy, general counseling, } \\
\text { pharmacotherapy }\end{array}$ & & & 1 & & 1 & \\
\hline & $\begin{array}{l}\text { General Counseling + physiotherapy } \\
\text { + Social counseling }\end{array}$ & & & 1 & & 1 & \\
\hline & $\begin{array}{l}\text { General Counseling and } \\
\text { Pharmacotherapy or just General Co.. }\end{array}$ & & 1 & & & 1 & \\
\hline Psychosocial & I Empowerment workshop & & & 2 & & 2 & \\
\hline & General Counseling & 1 & 1 & 1 & 1 & 2 & 2 \\
\hline $\begin{array}{l}\text { Anxiety } \\
\text { Unclear }\end{array}$ & Improved & & & & & & \\
\hline
\end{tabular}

multi-disciplinary intervention arms that targeted anxiety (all pre- and post-test designs) and documented improved anxiety symptoms included the following components: (1) pharmacotherapy and general counseling; (2) pharmacotherapy and CBT (not including exposure); and (3) physiotherapy, pharmacotherapy, CBT (with exposure), and EMDR. ${ }^{83,93,94}$ Each of these three intervention arms had pharmacotherapy components, two had CBT components, and one each had general counseling or physiotherapy components. Among the four multi-disciplinary intervention arms that did not show improvement (including two trials with a convenience or natural control), four included general counseling components, three had pharmacotherapy components and three included physiotherapy. ${ }^{41,42,108,112}$
There were six intervention arms among the psychosocial group of therapies that addressed anxiety among other symptoms (Figure 12). Two of these intervention arms (both of general counseling) had a comparison group (one RCT, one convenience control) but neither documented an improvement in anxiety symptoms. ${ }^{31,89}$ Only two psychosocial intervention arms resulted in improved anxiety symptoms (both Empowerment Workshops) but the evidence was limited to pre- and post-test study designs. ${ }^{45,98}$

Both of the two intervention arms from the Holistic (Qigong and T'ai Chi) and Psychodynamic (Yalom Group Psychotherapy) types of therapies documented improvement in anxiety symptoms. ${ }^{55,91}$ The level of evidence for the two intervention arms was from anecdotal reports of impact. 
Effectiveness of interventions for functioning among adult survivors of torture and other systematic violence

Summary: Among interventions for adult survivors of torture and other systematic violence that address dysfunction, there are no interventions with sufficient evidence at this time to recommend use by NGO programs. Promising interventions that are currently recommended for priority research among adult survivors of torture and other systematic violence with function loss are the following: Multi-disciplinary therapies (including pharmacotherapy); Pharmacotherapy (alone); and Cognitive Behavioral Therapies (various).

Eighteen intervention arms in the review targeted dysfunction. Dysfunction was measured with questionnaires (15) or by other methods (2); one intervention arm did not report any type of assessment method. Six of seven intervention arms from the CBT group of therapies resulted in improved functioning (Figure 13). One CBT intervention arm was part of an RCT (CBT without exposure) and another (Stress Inoculation Training) used convenience or natural control for comparison. ${ }^{32,105}$ The other five CBT intervention arms were cognitive processing therapy with an interpreter (with a pre- and post-test design), CBT with an exposure component (with a post-test only design), two arms of TT (pre- and post-test design) and an arm of NET (pre- and post-test design). ${ }^{29,} 100$ The one intervention arm among the CBT therapies that did not document improvement in functioning (results unclear) was one of the TT arms using a pre- and post-test study design. ${ }^{28}$

Four of five multi-disciplinary therapy intervention arms resulted in improved function (Figure 13). One of these used a convenience or natural control for comparison (physiotherapy, pharmacotherapy, general counseling, plus legal services). ${ }^{108}$ Three other multi-disciplinary intervention arms (all pre- and post-test measures) documented improved functioning and had the following components, respectively: (1) pharmacotherapy plus general counseling; and, (2) physiotherapy, pharmacotherapy, CBT (with exposure) plus EMDR. ${ }^{62.71,94}$ Pharmacotherapy was a common component of all three of these multi-disciplinary intervention arms. The findings of one multi-disciplinary intervention arm (pharmacotherapy plus general counseling) were unclear regarding changes in function; the evidence for this intervention arm was from a post-test only study design. ${ }^{35}$ All three intervention arms from one study in the pharmacotherapy (only) group documented improved functioning, all of them with pre- and post-test measures as the level of evidence. ${ }^{104}$

Among the three intervention arms from the Psychosocial type of therapy, two provided general counseling. ${ }^{31,45,107}$ One of these general counseling intervention arms demonstrated improved function (pre- and post-test study design) and the other (with a convenience or natural control) had unclear results. ${ }^{31,107}$

\section{Effectiveness of interventions for pain among adult survivors of torture and other systematic violence}

Summary: At this time, there are no interventions for adult survivors of torture and other systematic violence that address pain with sufficient evidence to recommend use by NGO programs. Promising interventions that are currently recommended for priority research among adult survivors of torture and other systematic violence with pain are the following: NET and CBT with biofeedback.

Eight intervention arms in the review targeted pain. Pain was measured with 
Figure 13: Number of intervention arms targeting function by type of therapy, type of evidence and impact

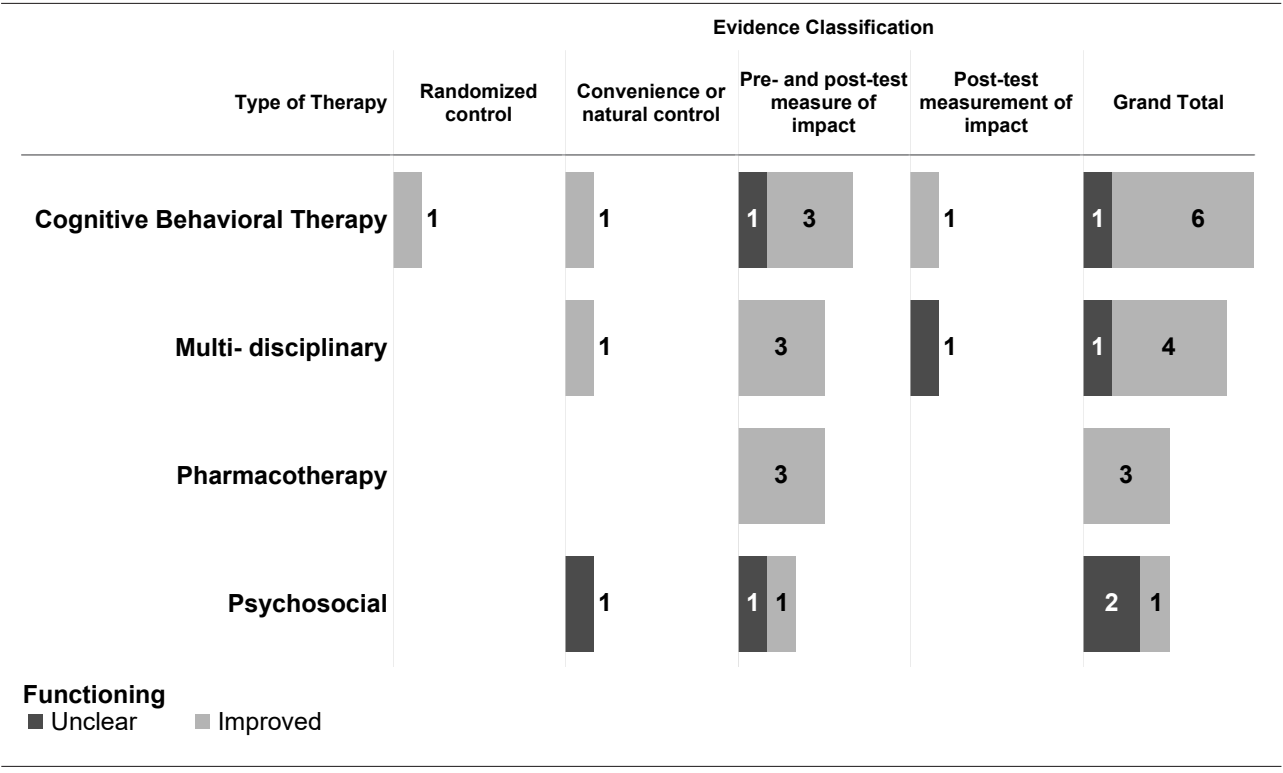

Figure 14: Number of intervention arms targeting pain by type of therapy, type of evidence and impact

\begin{tabular}{|c|c|c|c|c|c|}
\hline \multirow[b]{2}{*}{ Type of Therapy } & \multirow[b]{2}{*}{ Intervention Arm } & \multicolumn{4}{|c|}{ Evidence Classification } \\
\hline & & $\begin{array}{l}\text { Randomized } \\
\text { control }\end{array}$ & $\begin{array}{c}\text { Pre- and } \\
\text { post-test } \\
\text { measure of } \\
\text { impact }\end{array}$ & $\begin{array}{l}\text { Anecdotal } \\
\text { reports of } \\
\text { impact }\end{array}$ & Grand Total \\
\hline \multirow{3}{*}{$\begin{array}{l}\text { Cognitive Behavioral } \\
\text { Therapy }\end{array}$} & CBT Biofeedback & 1 & 1 & & 2 \\
\hline & CBT Biofeedback + physical activity & 1 & & & 1 \\
\hline & Narrative Exposure Therapy & 1 & & & 1 \\
\hline Multi- disciplinary & Physiotherapy + general counseling & & 1 & & 1 \\
\hline Multi-therapy & Biofeedback + NET & & 1 & & 1 \\
\hline Holistic Therapy & Traditional Chinese Medicine & & 1 & 1 & 1 \\
\hline \multicolumn{6}{|l|}{$\begin{array}{l}\text { Pain } \\
\text { U Unclear } \square \text { Improved }\end{array}$} \\
\hline
\end{tabular}


structured diagnostic interviews (1) or questionnaires (7). The majority of the intervention arms in the database that targeted pain symptoms documented improvement (Figure 14). Three of four CBT intervention arms targeting pain symptoms included a component of biofeedback and all showed improvements in pain symptoms: two intervention arms were RCTs and one was a pre- and post-test design. ${ }^{79}, 85$ Improvements in pain symptoms were also documented in the following: a NET intervention arm using an RCT design $^{87}$; a multi-disciplinary intervention arm with physiotherapy and general counseling components using a pre- and post-test design $^{46}$; and, a multi-therapy intervention arm with both biofeedback and NET components using a pre- and post-test design. ${ }^{84}$ Of the two intervention arms using traditional Chinese medicine, one documented improvement in pain (pre- and post-test design) and the other, an anecdotal report, had unclear findings. ${ }^{59,96}$

\section{Effectiveness of interventions for panic} attacks among adult survivors of torture and other systematic violence

Summary: Among interventions for adult survivors of torture and other systematic violence that address panic attacks, no intervention has sufficient evidence at this time to recommend it for use by NGO programs. CBT with exposure components is a research priority for adult survivors of torture and other systematic violence with panic attacks.

Six intervention arms targeted panic attacks. Panic attacks were measured primarily with questionnaires ${ }^{4}$, and one study used a structured diagnostic interview; one intervention arm did not report any type of assessment method. There were four intervention arms among the CBT group of therapies that targeted panic attack symptoms. ${ }^{60,61,63,64}$ All four intervention arms resulted in improved symptoms. Three of the four intervention arms used an RCT design (two CBT interventions with exposure, and one CBT with panic exposure), and one used a pre- and post-test design (CBT with both trauma and panic exposure); all four of these intervention arms were carried out by the same research team.

Intervention arms of two other types of therapies (Multi-disciplinary, Holistic) targeted panic attacks, but none of these provided clear results as to whether panic attack symptoms changed by the end of treatment, and none included a comparison group. ${ }^{36,74}$ The intervention arm of multidisciplinary treatment (pharmacotherapy and CBT components) had a pre- and post-test design, and the other intervention arm (dance/movement therapy) was an anecdotal report.

Effectiveness of interventions for substance abuse among adult survivors of torture and other systematic violence Summary: Among interventions for adult survivors of torture and other systematic violence that address substance abuse, there are no interventions with sufficient evidence at this time to recommend for use by NGO programs or as research priorities.

One intervention arm that targeted substance abuse was assessed by an informal interview. ${ }^{70}$ The impact of this intervention arm of general counseling, based on an anecdotal report, was unclear to those coding the studies.

\section{Discussion and recommendations}

The quality of reporting in the literature varied considerably. As we might expect, the 
quality of documentation of RCTs was generally good. With RCTs, the methods and outcomes were clearly reported in most cases, as publication of RCTs is influenced by the CONSORT Guidelines.117 In contrast, as the level of evidence lowered from RCTs to anecdotal reports of study impact, there was a tendency to be less clear about methods used and study outcomes. We recommend the following standards in the reporting of mental health studies of survivors of torture and other systematic violence for both authors and journals: (1) inclusion and exclusion criteria for study participants that describe the participants' exposure to torture or systematic violence;

(2) in multi-arm comparison studies a description of how participants were allocated to the different arms; (3) a description of the therapy components included in each arm of the study; (4) a description of what local instrument adaptation and testing was done prior to study implementation; (5) locating where readers can obtain a detailed description of the therapy provided in each arm; (6) in multi-arm comparison studies a description of what therapy components, if any, control/comparison participants received; (7) a description of the primary outcome measures and how they were assessed; and (8) a description of how symptoms and other outcome measures changed including with respect to a comparison group, if applicable (effect sizes for RCTs).

We recommend that intervention priorities for use in NGO programs should be those mental health interventions with an evidence base coming from at least several RCTs and carried out by at least more than one team of independent investigators. These should be interventions that are proven to work in multiple settings. If NGOs are going to provide services before research is available in their local settings, the literature suggests using CBT with exposure components is most likely to address symptoms of PTSD, anxiety, and depression in survivors of torture and trauma (Table 2). For NGOs that want to address dysfunction, pain, panic attacks, or substance abuse among survivors of torture and other systematic violence, there is insufficient scientific evidence to warrant recommendation of any particular intervention at the time of writing.

Whatever intervention NGOs or other service providers choose, they need to provide evidence of impact in their program. This is true even when choosing an intervention like CBT that has been proven in multiple other settings as it may not be as effective in a different setting. Therefore, it is important to confirm that outcomes move in the expected direction (via pre and posttesting at minimum, or controlled trials if possible).

There are some important practical implications to the overall recommendation that CBT with exposure is currently the most evidence-based treatment approach for survivors of torture and trauma. First, research manuscripts rarely give details of what was actually included in the treatment (e.g., the components), or how processes such as training and supervision were conducted. These details are critical for an NGO to understand how to implement recommended treatments. We recommend that researchers begin to document and disseminate these details for treatments. For now, NGOs must contact researchers and practitioners for details of particular interventions. Second, CBT interventions have similar components so the recommendation to use CBT comes without a recommendation for a particular "manual". There is emerging literature on transdiagnostic or 
Table 2: Priorities for programs and research by mental health problem

\begin{tabular}{|c|c|c|}
\hline $\begin{array}{l}\text { Mental Health } \\
\text { Problem }\end{array}$ & $\begin{array}{l}\text { Priority for torture survivor } \\
\text { programs }\end{array}$ & Priority for torture survivor research \\
\hline PTSD & $\begin{array}{l}\text { Cognitive Behavioral Therapy } \\
\text { with exposure components }\end{array}$ & $\begin{array}{l}\text { 1. Narrative Exposure Therapy (NET) } \\
\text { 2. Interpersonal Therapy (IPT) } \\
\text { 3. Pharmacotherapy (alone) } \\
\text { 4. Multi-disciplinary therapies (many with CBT } \\
\text { and pharmacotherapy components) }\end{array}$ \\
\hline Depression & $\begin{array}{l}\text { Cognitive Behavioral Therapy } \\
\text { with exposure components }\end{array}$ & $\begin{array}{l}\text { 1. Narrative Exposure Therapy (NET) } \\
\text { 2. Interpersonal Therapy (IPT) } \\
\text { 3. Pharmacotherapy (alone) } \\
\text { 4. Multi-disciplinary therapies (many with CBT } \\
\text { and pharmacotherapy components) }\end{array}$ \\
\hline Anxiety & $\begin{array}{l}\text { Cognitive Behavioral Therapy } \\
\text { with exposure components }\end{array}$ & $\begin{array}{l}\text { 1. Cognitive Behavioral Therapy with biofeedback } \\
\text { 2. Pharmacotherapy (alone) }\end{array}$ \\
\hline Dysfunction & (None) & $\begin{array}{l}\text { 1. Multi-disciplinary therapies (including } \\
\text { pharmacotherapy) } \\
\text { 2. Pharmacotherapy (alone) } \\
\text { 3. Cognitive Behavioral Therapies (various) }\end{array}$ \\
\hline Pain & (None) & $\begin{array}{l}\text { 1. Narrative Exposure Therapy (NET) } \\
\text { 2. CBT with biofeedback }\end{array}$ \\
\hline Panic Attacks & (None) & $\begin{array}{l}\text { Cognitive Behavioral Therapy with exposure } \\
\text { components }\end{array}$ \\
\hline Substance Abuse & (None) & Stress management classes \\
\hline
\end{tabular}

common elements approaches, or approaches that teach a range of elements within evidence-based treatments that can be delivered in varying combinations to address a range of problems. ${ }^{18-123}$ This suggests that there may be some flexibility in using CBT elements.

We propose the following criteria in selecting priorities for mental health research for survivors of torture and other systematic violence in order of decreasing priority: (a) an intervention has shown effectiveness in RCTs but only a few RCTs have been conducted and/or they were of low quality (for example, some studies have been done with small sample sizes, e.g., 22$)^{82}$; (b) an intervention has shown effectiveness with
RCTs but not by independent investigators; (c) an intervention has not been tested with several RCTs but other study designs suggest effectiveness; or (d) an intervention has shown mixed results with several RCTs. We focus on RCTs because many studies (and therefore interventions) in the database demonstrated improvements in mental health symptoms only on the basis of preand post-test study designs. They are therefore subject to multiple biases with respect to recruitment, loss in follow-up, impacts of factors outside the program, and, where recruitment is on the basis of severity, regression to the mean.

Several outcomes were excluded from our analyses for reasons related to concep- 
tual clarity. These were multidimensional symptom measures used to examine change in secondary outcomes and multiple categories of symptoms that were byproducts of interventions targeted at other specific diagnoses. ${ }^{75,112}$ By not addressing these outcomes in our recommendations, we in no way mean to dismiss their importance to survivors of torture and other systematic violence - indeed, decreasing symptoms across domains of distress is likely more important to those seeking treatment than eliminating specific diagnoses per se.

\section{Limitations}

There is a selection bias in the review in that we only included studies published in English, and therefore the noted lack of studies from Latin America, Eastern Europe and some other regions may be due to this limitation. Another limitation is that the level of evidence for the studies was based on the type of study (e.g., RCT, anecdotal report) and not a rating of the quality of the study. Therefore, even if two RCTs had varying quality, they were given the same weight in our recommendations. Finally, the authors were limited to the information in the published articles and therefore were not able to confirm aspects such as the crosscultural validity and psychometrics of all the instruments used.

\section{Conclusions}

CBT that includes exposure components shows the best evidence for effectively addressing the mental health symptoms of PTSD, depression, and anxiety among survivors of torture and systematic violence. We recommend that NGOs providing mental health services to survivors of torture and other systematic violence use CBT with exposure components to address PTSD, depression and anxiety, until such time as other interventions are found to be effective, especially from trials in similar populations. There are several priorities for mental health research for survivors of torture and other systematic violence and these priorities differ depending on the presenting problem (Table 2). Overall, we recommend more RCTs due to the limited evidence base for interventions, including collaborations between service providers and researchers. The highest priorities for RCTs are the following interventions that show promise for addressing more than one mental health problem: Narrative Exposure Therapy (NET); Interpersonal Therapy (IPT); pharmacotherapy (alone); and multi-disciplinary therapies (with CBT and pharmacotherapy components).

We hope that this paper provides direction for policy makers, funders, organizations and providers working with populations that have experienced torture and/or trauma. The timing is appropriate as there are now available interventions that have empirical support and have been successfully implemented in lower resource settings with para-professionals following certain training procedures. Knowledge of these interventions and of the need for more research could be used on the policy level to support and encourage the use and investigation of empirically supported treatments. Clinical programs should contact the investigators of such studies to obtain further detailed information on the process of adaptation, training and supervision across various settings. This paper ideally will contribute to wider use of empirically validated, effective treatment for torture and trauma populations and expansion of the evidence base consisting of more rigorous research. 


\section{Acknowledgements}

The work in this article was supported by the SPANS-IETTS cooperative agreement DFD-A-00-08-00308-00 between the Johns Hopkins University and the USAID Victims of Torture Fund (VOT). The SPANSIETTS cooperative agreement was implemented to support research and provide technical assistance to VOT grantees and other service organizations that provide community-based mental health interventions for torture survivors.

The views of the authors expressed in this article are his or her own and not the official position of The Johns Hopkins University or the US Agency for International Development (USAID).

\section{References}

1. Grodin M, Tarantola D, Annas G, Gruskin S, editors. Health and Human Rights in a Changing World: Taylor \& Francis; 2013.

2. Ortmann J, Genefke IK, Jakobsen L, Lunde I. Rehabilitation of torture victims: an interdisciplinary treatment model. American Journal of Social Psychiatry. 1987;7(3):161-7.

3. Quiroga J, Jaranson JM. Politically-motivated torture and its survivors. Torture. 2005;16(2-3).

4. Sinnerbrink I, Silove D, Field A, Steel Z, Manicavasagar V. Compounding of premigration trauma and postmigration stress in asylum seekers. The Journal of Psychology: Interdisciplinary and Applied. 1997;131(5):463-70.

5. Basoglu M. Prevention of torture and care of survivors. An integrated approach. JAMA: Journal of the American Medical Association. 1993;279(5):606-11.

6. Basoglu M, Paker M, Paker O, Ozmen E, Marks I, Incesu C, et al. Psychological effects of torture: a comparison of tortured with nontortured political activists in Turkey. American Journal of Psychiatry. 1994;151(1):76-81.

7. Holtz TH. Refugee trauma versus torture trauma: a retrospective controlled cohort study of Tibetan refugees. Journal of Nervous \& Mental Disease. 1998;186(1):24-34.

8. Jaranson JM, Butcher J, Halcon L, Johnson DR, Robertson C, Savik K, et al. Somali and Oromo refugees: correlates of torture and trauma history. Am J Public Health. 2004 Apr;94(4):591-8.

9. de Jong JTVM, Komproe IH, Van Ommeren M, El Masri M, Araya M, Khaled N, et al. Lifetime events and posttraumatic stress disorder in 4 postconflict settings. JAMA. 2001 Aug 1;286:555-62.

10. Mollica RF. Surviving torture. New England Journal of Medicine. 2004 Jul 1;351(1):5-7.

11. Shresta NM, Sharma B, van Ommeren $M$, Regmi S, Makaju R, Komproe IH, et al. Impact of torture on refugees displaced within the developing world: Symptomatology among Bhutanese refugees in Nepal. JAMA. 1998 Aug 5;280(5):443-8.

12. Amodeo M, Robb N, Peou S, Tran H. Adapting mainstream substance-abuse interventions for Southeast Asian clients. Families in Society. 1996;77(7):403-13.

13. Basoglu M, Jaranson JM, Mollica RF, Kastrup $M$. Torture and mental health: A research overview. In: Garrity E, Keane TM, Tuma F, editors. The mental health consequences of torture. New York: Plenum Publishers; 2001. p. 35-62.

14. Forrest D. The physical after-effects of torture. Forensic Sci Int. 1995 Nov 30;76(1):77-84.

15. Forrest SH. Examination for the late physical after effects of torture. J Clin Forensic Med. 1999 Mar;6(1):4-13.

16. Rasmussen A, Rosenfeld B, Reeves K, Keller AS. The effects of torture-related injuries on psychological distress in a Punjabi Sikh sample. J Abnorm Psychol. 2007 Nov;116(4):734-40.

17. Rasmussen OV. Medical aspects of torture. Dan Med Bull. 1990 Jan;37 Suppl 1:1-88.

18. Keatley E, Ashman T, Im B, Rasmussen A. Self report traumatic brain injury among refugee survivors of torture. J Head Trauma Rehabil. 2013 Nov-Dec;28(6):E8-E13. doi: 10.1097/ HTR.0b013e3182776a70..

19. Chu T, Keller AS, Rasmussen A. Effects of postmigration factors on PTSD outcomes among immigrant survivors of political violence. J Immigr Minor Health. 2013 Oct;15(5):890-7.

20. Raghavan S, Rasmussen A, Rosenfeld B, Keller AS. Correlates of symptom reduction in treatment-seeking survivors of torture. Psychological Trauma: Theory, Research, Practice, and Policy. 2013 Jul;5(4):377-83.

21. Smith CH. Torture Victims Relief Act of 1998 (P. L. 105-320). In: HHS, editor. H R 4309. Washington, D. C.: United States Printing Office; 1998 .

22. United Nations. General Assembly resolution 
$36 / 15$, United Nations voluntary fund for victims of torture, A/RES/36/151 (16 December 1981), Available: undocs.org/A/RES/36/151.

23. McFarlane CA, Kaplan I. Evidence-based psychological interventions for adult survivors of torture and trauma: a 30-year review. Transcult Psychiatry. 2012 Jul;49(3-4):539-67.

24. Thomas BH, Ciliska D, Dobbins M, Micucci S. A process for systematically reviewing the literature: providing the research evidence for public health nursing interventions. Worldviews Evid Based Nurs / Sigma Theta Tau International Honor Society of Nursing. 2004;1(3):176-84.

25. Crumlish N, O'Rourke K. A systematic review of treatments for post-traumatic stress disorder among refugees and asylum-seekers. J Nerv Ment Dis. 2010 Apr;198(4):237-51

26. Adenauer H, Catani C, Gola H, Keil J, Ruf M, Schauer M, et al. Narrative exposure therapy for PTSD increases top-down processing of aversive stimuli - evidence from a randomized controlled treatment trial. BMC Neurosci. 2011 Dec 19;12:127.

27. Agger I, Igreja V, Kiehle R, Polatin P. Testimony ceremonies in Asia: integrating spirituality in testimonial therapy for torture survivors in India, Sri Lanka, Cambodia, and the Philippines. Transcult Psychiatry. 2012 Jul;49(3-4):568-89.

28. Agger I, Raghuvanshi L, Shabana S, Polatin P, Laursen LK. Testimonial therapy: a pilot project to improve psychological wellbeing among survivors of torture in India. Torture: quarterly journal on rehabilitation of torture victims and prevention of torture. 2009;19(3):204-17.

29. Başoğlu M, Ekblad S, Bäärnhielm S, Livanou M. Cognitive-behavioral treatment of tortured asylum seekers: a case study. J Anxiety Disord. 2004;18(3):357-69.

30. Başoğlu M, Marks IM, Sengün S. Amitriptyline for PTSD in a torture survivor: A case study. Journal of traumatic stress. 1992 Jan;5(1):77-83.

31. Bass J, Poudyal B, Tol W, Murray L, Nadison $\mathrm{M}$, Bolton P. A controlled trial of problem-solving counseling for war-affected adults in Aceh, Indonesia. Soc Psychiatry Psychiatr Epidemiol. 2012 Feb;47(2):279-91.

32. Bass JK, Annan J, McIvor Murray S, Kaysen D, Griffiths S, Cetinoglu T, et al. Controlled Trial of Psychotherapy for Congolese Survivors of Sexual Violence. N Engl J Med. 2013 Jun 6;368(23):2182-91.

33. Bichescu D, Neuner F, Schauer M, Elbert T. Narrative exposure therapy for political imprisonment-related chronic posttraumatic stress disorder and depression. Behav Res Ther. 2007

Sep;45(9):2212-20.

34. Boehnlein JK, Kinzie JD, Ben R, Fleck J.

One-year follow-up study of posttraumatic stress disorder among survivors of Cambodian concentration camps. Am J Psychiatry. 1985 Aug;142(8):956-9.

35. Boehnlein JK, Kinzie JD, Sekiya U, Riley C, Pou K, Rosborough B. A ten-year treatment outcome study of traumatized Cambodian refugees. J Nerv Ment Dis. 2004 Oct;192(10):65863.

36. Bouwer C, Stein DJ. Survivors of torture presenting at an anxiety disorders clinic: symptomatology and pharmacotherapy. J Nerv Ment Dis. 1998 May;186(5):316-8.

37. Boynton L, Bentley J, Strachan E, Barbato A, Raskind M. Preliminary findings concerning the use of prazosin for the treatment of posttraumatic nightmares in a refugee population. J Psychiatr Pract. 2009 Nov;15(6):454-9.

38. Brick A. Torture victims after psychotherapy- a two year follow-up. Torture. 2001;11(2):55-8.

39. Bryant RA, Ekasawin S, Chakrabhand S, Suwanmitri S, Duangchun O, Chantaluckwong T. A randomized controlled effectiveness trial of cognitive behavior therapy for post-traumatic stress disorder in terrorist-affected people in Thailand. World Psychiatry: official journal of the World Psychiatric Association. 2011 Oct;10(3):205-9.

40. Callaghan K. Movement psychotherapy with adult survivors of political torture and organized violence. The Arts in Psychotherapy. 1993;20(5):411-21.

41. Carlsson JM, Mortensen EL, Kastrup M. A follow-up study of mental health and healthrelated quality of life in tortured refugees in multidisciplinary treatment. J Nerv Ment Dis. 2005 Oct;193(10):651-7.

42. Carlsson JM, Olsen DR, Kastrup M, Mortensen EL. Late mental health changes in tortured refugees in multidisciplinary treatment. J Nerv Ment Dis. 2010 Nov;198(11):824-8.

43. Charlés LL. Producing evidence of a miracle: exemplars of therapy conversation with a survivor of torture. Fam Process. 2012 Mar;51(1):25-42.

44. Cienfuegos AJ, Monelli C. The testimony of political repression as a therapeutic instrument. Am J Orthopsychiatry. 1983 Jan;53(1):43-51.

45. Curling P. The effectiveness of empowerment workshops with torture survivors. Torture. 2005;15(1):9-15.

46. Danneskiold-Samsøe B, Bartels EM, Genefke 
I. Treatment of torture victims--a longitudinal clinical study. Torture: quarterly journal on rehabilitation of torture victims and prevention of torture. 2007;17(1):11-7.

47. Drozdek B. Follow-up study of concentration camp survivors from Bosnia-Herzegovina: three years later. Journal of Nervous and Mental Disease. 1997 Nov;185(11):690-4.

48. Dybdahl R. Children and mothers in war: an outcome study of a psychosocial intervention program. Child Dev. 2001 JulAug;72(4):1214-30.

49. Fernandez M, Pissiota A, Frans O, von Knorring L, Fischer H, Fredrikson M. Brain function in a patient with torture related post-traumatic stress disorder before and after fluoxetine treatment: a positron emission tomography provocation study. Neurosci Lett. 2001 Jan 12;297(2):101-4.

50. Fischman Y, Ross J. Group treatment of exiled survivors of torture. Am J Orthopsychiatry. 1990 Jan;60(1):135-42.

51. Gillespie K, Duffy M, Hackmann A, Clark DM. Community based cognitive therapy in the treatment of posttraumatic stress disorder following the Omagh bomb. Behav Res Ther. 2002 Apr;40(4):345-57.

52. Goodsmith L. Beyond where it started: a look at the "Healing Images" experience. Torture. 2007;17(3):222-32.

53. Gray AEL. The Body Remembers: Dance/ Movement Therapy with an Adult Survivor of Torture. American Journal of Dance Therapy. 2001 Mar;23(1):29-43.

54. Grey N, Young K. Cognitive Behaviour Therapy with Refugees and Asylum Seekers Experiencing Traumatic Stress Symptoms. Behavioural and Cognitive Psychotherapy. 2008 Jan;36(1):3-19.

55. Grodin MA, Piwowarczyk L, Fulker D, Bazazi AR, Saper RB. Treating survivors of torture and refugee trauma: a preliminary case series using qigong and t'ai chi. J Altern Complement Med. 2008 Sep;14(7):801-6.

56. Halcón LL, Robertson CL, Monsen KA. Evaluating Health Realization for Coping Among Refugee Women. J Loss Trauma. 2010 Sep;15(5):408-25.

57. Halvorsen JØ, Stenmark H. Narrative exposure therapy for posttraumatic stress disorder in tortured refugees: a preliminary uncontrolled trial. Scand J Psychol. 2010 Dec;51(6):495-502.

58. Hensel-Dittmann D, Schauer M, Ruf M, Catani C, Odenwald M, Elbert T, et al. Treatment of traumatized victims of war and torture: A randomized controlled comparison of narrative exposure therapy and stress inoculation training. Psychother Psychosom. 2011;80(6):345-52.

59. Highfield ES, Lama P, Grodin MA, Kaptchuk TJ, Crosby SS. Acupuncture and traditional Chinese medicine for survivors of torture and refugee trauma: a descriptive report. J Immigr Minor Health. 2012 Jun;14(3):433-40.

60. Hinton DE, Chhean D, Pich V, Safren SA, Hofmann SG, Pollack MH. A randomized controlled trial of cognitive-behavior therapy for Cambodian refugees with treatment-resistant PTSD and panic attacks: a cross-over design. J Trauma Stress. 2005 Dec;18(6):617-29.

61. Hinton DE, Hofmann SG, Pollack MH, Otto MW. Mechanisms of efficacy of CBT for Cambodian refugees with PTSD: improvement in emotion regulation and orthostatic blood pressure response. CNS Neurosci Ther. 2009 Fall;15(3):255-63.

62. Hinton DE, Kredlow MA, Bui E, Pollack MH, Hofmann SG. Treatment change of somatic symptoms and cultural syndromes among Cambodian refugees with PTSD. Depress Anxiety. 2012 Feb;29(2):147-54

63. Hinton DE, Pham T, Tran M, Safren SA, Otto MW, Pollack MH. CBT for Vietnamese refugees with treatment-resistant PTSD and panic attacks: A Pilot Study. J Trauma Stress. 2004 Oct;17(5):429-33.

64. Hinton DE, Safren SA, Pollack MH, Tran M Cognitive-Behavior Therapy for vietnamese refugees with PTSD and comorbid panic attacks. Cognitive and Behavioral Practice. 2006;13(4):271-81.

65. Holmqvist R, Andersen K, Anjum T, Alinder B. Change in self-image and PTSD symptoms in short-term therapies with traumatized refugees. Psychoanalytic Psychotherapy. 2006;20(4):25165.

66. Igreja V, Kleijn WC, Schreuder BJN, Van Dijk JA, Verschuur M. Testimony method to ameliorate post-traumatic stress symptoms. Community-based intervention study with Mozambican civil war survivors. Br J Psychiatry. 2004 Mar; 184:251-7.

67 . Jensen BS. Treatment of a multitraumatized tortured refugee needing an interpreter with exposure therapy. Case Rep Psychiatry. 2013;2013:197323. doi: 10.1155/2013/197323. Epub 2013 Feb 6

68. Johnson C, Shala M, Sejdijaj X, Odell R, Dabishevci K. Thought Field Therapy-soothing the bad moments of Kosovo. Journal of clinical psychology. J Clin Psychol. 2001 Oct;57(10):123740 . 
69. Kennedy P. Working with survivors of torture in Sarajevo with Reiki. Complement Ther Nurs Midwifery. 2001 Feb;7(1):4-7.

70. Kieft B, Jordans MJD, de Jong JTVM, Kamperman AM. Paraprofessional counselling within asylum seekers' groups in the Netherlands: transferring an approach for a non-western context to a European setting. Transcult Psychiatry. 2008 Mar;45(1):105-20.

71. Kinzie JD, Kinzie JM, Sedighi B, Woticha A, Mohamed H, Riley C. Prospective one-year treatment outcomes of tortured refugees: a psychiatric approach. Torture. 2012;22(1):1-10.

72. Kinzie JD, Leung P. Clonidine in Cambodian patients with posttraumatic stress disorder. J Nerv Mental Dis. 1989 Sep;177(9):546-50.

73. Kivling-Bodén G, Sundbom E. Life situation and posttraumatic symptoms: a follow-up study of refugees from the former Yugoslavia living in Sweden. Nord J Psychiatry. 2001;55(6):401-8.

74. Koch SC, Weidinger-von der Recke B. Traumatised refugees: An integrated dance and verbal therapy approach. The Arts in Psychotherapy. 2009;36(5):289-96.

75. Kruse J, Joksimovic L, Cavka M, Wöller W, Schmitz N. Effects of trauma-focused psychotherapy upon war refugees. J Trauma Stress. 2009 Dec;22(6):585-92.

76. Kucukalić A, Bravo-Mehmedbasić A. Torture victims and mechanisms of coping with stress. Psychiatr Danub. 2003 Jun;15(1-2):25-8.

77. Larsen H, Pagaduan-Lopez J. Stress-tension reduction in the treatment of sexually tortured women--an exploratory study. J Sex Marital Ther. 1987 Fall;13(3):210-8.

78. Lekskes J. Appraisal of psychosocial interventions in Liberia. Intervention (Amstelveen). 2007;5(1):18-26.

79. Liedl A, Müller J, Morina N, Karl A, Denke C, Knaevelsrud C. Physical activity within a CBT intervention improves coping with pain in traumatized refugees: Results of a randomized controlled design. Pain Med. 2011 Feb;12(2):23445.

80. Maercker A, Gäbler I, O'Neil J, Schützwohl M, Müller M. Long-term trajectories of PTSD or resilience in former East German political prisoners. Torture. 2013;23(1):15-27.

81. Manneschmidt S, Griese K. Evaluating psychosocial group counselling with afghan women: is this a useful intervention? Torture. 2009;19(1):41-50.

82. Meffert SM, Abdo AO, Alla OAA, Elmakki YOM, Omer AA, Yousif S, Metzler TJ, Marmar CR. A pilot randomized controlled trial of interpersonal psychotherapy for Sudanese refugees in Cairo, Egypt. Psychological Trauma: Theory, Research, Practice, and Policy, Vol 6(3), May 2014, 240-249.

83. Mollica RF, Wyshak G, Lavelle J, Truong T, Tor S, Yang T. Assessing symptom change in Southeast Asian refugee survivors of mass violence and torture. Am J Psychiatry. 1990 Jan;147(1):83-8.

84. Morina N, Maier T, Bryant R, Knaevelsrud C, Wittmann L, Rufer M, Schnyder U, Müller J. Combining biofeedback and Narrative Exposure Therapy for persistent pain and PTSD in refugees: a pilot study. Eur J Psychotraumatol. 2012;3.

85. Muller J, Karl A, Denke C, Mathier F, Dittmann J, Rohleder N, Knaevelsrud C. Biofeedback for pain management in traumatised refugees. Cogn Behav Ther. 2009;38(3):184-90.

86. Munczek DS. Short-term treatment of a Central American torture survivor. Psychiatry. 1998 Winter;61(4):318-29.

87. Neuner F, Kurreck S, Ruf M, Odenwald M, Elbert T, Schauer M. Can asylum-seekers with posttraumatic stress disorder be successfully treated? A randomized controlled pilot study. Cogn Behav Ther. 2010;39(2):81-91.

88. Neuner F, Onyut PL, Ertl V, Odenwald M, Schauer E, Elbert T. Treatment of posttraumatic stress disorder by trained lay counselors in an African refugee settlement: A randomized controlled trial. J Consult Clin Psychol. 2008 Aug;76(4):686-94.

89. Neuner F, Schauer M, Klaschik C, Karunakara U, Elbert T. A Comparison of Narrative Exposure Therapy, Supportive Counseling, and Psychoeducation for Treating Posttraumatic Stress Disorder in an African Refugee Settlement. J Consult Clin Psychol. 2004 Aug;72(4):579-87.

90. Neuner F, Schauer M, Roth WT, Elbert T. A Narrative Exposure Treatment as intervention in a refugee camp: a case report. Behav Cogn Psychother. 2002;30(02):205-9.

91. Nicholson BL, Kay DM. Group treatment of traumatized Cambodian women: a culture-specific approach. Soc Work. 1999 Sep;44(5):4709.

92. Nieves-Grafals S. Brief therapy of civil war-related trauma: a case study. Cultur Divers Ethnic Minor Psychol. 2001 Nov;7(4):387-98.

93. Otto MW, Hinton D, Korbly NB, Chea A, Ba $\mathrm{P}$, Gershuny BS, et al. Treatment of pharmacotherapy-refractory posttraumatic stress disorder among Cambodian refugees: a pilot study of combination treatment with cognitive-behavior 
therapy vs sertraline alone. Behav Res Ther. 2003;41(11):1271-6.

94. Palic S, Elklit A. An explorative outcome study of CBT-based multidisciplinary treatment in a diverse group of refugees from a Danish treatment centre for rehabilitation of traumatized refugees. Torture. 2009;19(3):248-70.

95. Paunovic N, Ost LG. Cognitive-behavior therapy vs exposure therapy in the treatment of PTSD in refugees. Behav Res Ther. 2001;39(10):1183-97.

96. Pease M, Sollom R, Wayne P. Acupuncture for refugees with posttraumatic stress disorder: initial experiences establishing a community clinic. Explore (NY). 2009 Jan-Feb;5(1):51-4.

97. Priebe S, Gavrilovic JJ, Matanov A, Franciskovic T, Knezevic G, Ljubotina D, Mehmedbasic AB, Schützwohl M. Treatment outcomes and costs at specialized centers for the treatment of PTSD after the war in former Yugoslavia. Psychiatr Serv. 2010;61(6):598-604.

98. Reeler T, Chitsike K, Maizva F, Reeler B. The Tree of Life: a community approach to empowering and healing the survivors of torture in Zimbabwe. Torture. 2009;19(3):180-93.

99. RennerW. The effectiveness of psychotherapy with refugees and asylum seekers: preliminary results from an Austrian study. J Immigr Minor Health. 2009 Feb;11(1):41-5.

100. Schulz PM, Marovic-Johnson D, Huber LC. Cognitive-Behavioral Treatment of Rape- and War-Related Posttraumatic Stress Disorder With a Female, Bosnian Refugee. Clinical Case Studies. 2006 Jun;5(3):191-208.

101. Schulz PM, Resick PA, Huber LC, Griffin MG. The Effectiveness of Cognitive Processing Therapy for PTSD With Refugees in a Community Setting. Cogn Behav Pract. 2006;13(4):322-31.

102. Schwail M, Rasras K. Group therapy for victims of torture and organized violence. Torture. 2002;12(2):55-7.

103. Schwarz-Langer G, Deighton RR, Jerg-Bretzke L, Weisker I, Traue HC. Psychiatric treatment for extremely traumatized civil war refugees from former Yugoslavia. Possibilities and limitations of integrating psychotherapy and medication. Torture. 2006;16(2):69-80.

104. Smajkic A, Weine S, Djuric-Bijedic Z, Boskailo E, Lewis J, Pavkovic I. Sertraline, paroxetine, and venlafaxine in refugee posttraumatic stress disorder with depression symptoms. J Trauma Stress. 2001;14(3):445-52.

105. Snodgrass LL, Yamamoto J, Frederick C, TonThat N, Foy DW, Chan L, et al. Vietnamese refugees with PTSD symptomatology: Interven- tion via a coping skills model. J Trauma Stress. 1993;6(4):569-75.

106. Stenmark H, Catani C, Neuner F, Elbert T, Holen A. Treating PTSD in refugees and asylum seekers within the general health care system. A randomized controlled multicenter study. Behav Res Ther. 2013;51(10):641-7.

107. Stepakoff S, Hubbard J, Katoh M, Falk E, Mikulu J-B, Nkhoma P, Omagwa Y. Trauma healing in refugee camps in Guinea: a psychosocial program for Liberian and Sierra Leonean survivors of torture and war. Am Psychol. 2006 Nov;61(8):921-32.

108. Tol WA, Komproe IH, Jordans MJD, Thapa SB, Sharma B, De Jong JTVM. Brief multi-disciplinary treatment for torture survivors in Nepal: a naturalistic comparative study. Int J Soc Psychiatry. 2009 Jan;55(1):39-56..

109. van Dijk JA, Schoutrop MJA, Spinhoven P. Testimony therapy: treatment method for traumatized victims of organized violence. Am J Psychother. 2003;57(3):361-73.

110. Wagner B, Schulz W, Knaevelsrud C. Efficacy of an internet-based intervention for posttraumatic stress disorder in Iraq: a pilot study. Psychiatry Res. 2012 Jan;195(1-2):85-8.

111. Weine SM, Kulenovic AD, Pavkovic I, Gibbons R. Testimony psychotherapy in Bosnian refugees: a pilot study. Am J Psychiatry. 1998 Dec;155(12):1720-6.

112. Westermeyer J. A matched pairs study of depression among Hmong refugees with particular reference to predisposing factors and treatment outcome. Soc Psychiatry Psychiatr Epidemiol. 1988;23(1):64-71

113. Yeomans PD, Forman EM, Herbert JD, Yuen E. A randomized trial of a reconciliation workshop with and without PTSD psychoeducation in Burundian sample. J Traum Stress. 2010;23(3):305-12.

114. Adler AB, Litz BT, Castro CA, Suvak M, Thomas JL, Burrell L, et al. A group randomized trial of critical incident stress debriefing provided to U.S. peacekeepers. J Traum Stress. 2008;21(3):253-63.

115. Derogatis L, Lipman R, Rickels K, Uhlenhuth E, Covi L. The Hopkins Symptom Checklist (HSCL): A measure of primary symptom dimensions. In: Pichot P, editor. Modern Problems in Pharmacopsychiatry. Vol. 7. Basel, Switzerland: Karger; 1974.

116. Sheehan DV, LecrubierY, Sheehan KH, Amorim P, Janavs J, Weiller E, Hergueta T, Baker R, Dunbar GC. The Mini-International Neuropsychiatric Interview (M.I.N.I.): the 
development and validation of a structured diagnostic psychiatric interview for DSM-IV and ICD-10. J Clin psychiatry. 1998;59 Suppl 20:22-33; quiz 4-57.

117. Schulz KF, Altman DG, Moher D. CONSORT 2010 statement: Updated guidelines for reporting parallel group randomised trials. Journal of Pharmacology \& Pharmacotherapeutics. 2010;1(2):100-7.

118. Murray LK, Dorsey S, Haroz E, Lee C, Alsiary MM, Haydary A, Weiss WM, Bolton P. A Common Elements Treatment Approach for Adult Mental Health Problems in Low- and MiddleIncome Countries. Cogn Behav Pract. 2014 May;21(2):111-123.

119. Clark DA. Cognitive behavioral therapy for anxiety and depression: possibilities and limitations of a transdiagnostic perspective. Cogn Behav Ther. 2009;38 Suppl 1:29-34.

120. Farchione TJ, Fairholme CP, Ellard KK, Boisseau CL, Thompson-Hollands J, Carl JR, Gallaghera MW, Barlowa DH. Unified protocol for transdiagnostic treatment of emotional disorders: a randomized controlled trial. Behavior Therapy. 2012;43(3):666-78.

121. McHugh RK, Murray HW, Barlow DH. Balancing fidelity and adaptation in the dissemination of empirically-supported treatments: The promise of transdiagnostic interventions. Behav Res Ther. 2009 Nov;47(11):946-53.

122. Bolton P, Bass JK, Zangana G, Kamal T, Murray S, Kaysen D, Lejuez CW, Lindgren K, Pagoto S, Murray LK, Van Wyk SS, Ahmed AM, Amin NM, Rosenblum M. A randomized controlled trial of mental health interventions for survivors of systematic violence in Kurdistan, Northern Iraq. BMC Psychiatry. 2014 Dec 31;14(1):360.

123. Bolton P, Lee C, Haroz EE, Murray L, Dorsey S, Robinson C, Ugueto AM, Bass J. A transdiagnostic community-based mental health treatment for comorbid disorders: development and outcomes of a randomized controlled trial among Burmese refugees in Thailand. PLoS medicine. 2014 Nov;11(11):e1001757. 